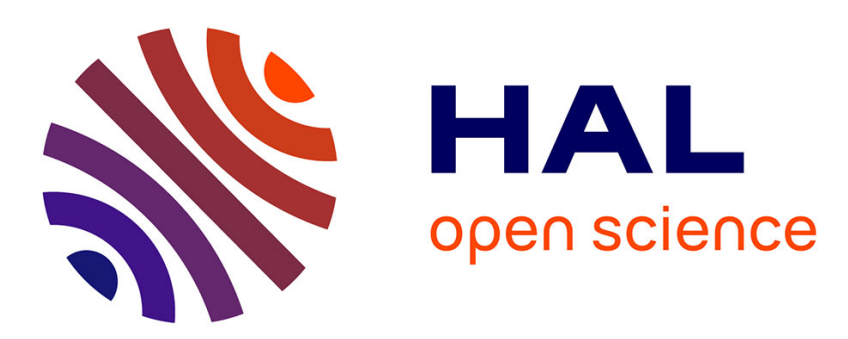

\title{
Degradation of gaseous nitriding of steel by lubricant contamination - Effect of in-situ pre-treatments
}

\author{
B. Guillot, S. Jegou, L. Barrallier
}

\section{To cite this version:}

B. Guillot, S. Jegou, L. Barrallier. Degradation of gaseous nitriding of steel by lubricant contamination - Effect of in-situ pre-treatments. Surface and Coatings Technology, 2017, 316, pp.59-70. 10.1016/j.surfcoat.2017.01.107 . hal-01479073

\section{HAL Id: hal-01479073 \\ https://hal.science/hal-01479073}

Submitted on 29 May 2017

HAL is a multi-disciplinary open access archive for the deposit and dissemination of scientific research documents, whether they are published or not. The documents may come from teaching and research institutions in France or abroad, or from public or private research centers.
L'archive ouverte pluridisciplinaire HAL, est destinée au dépôt et à la diffusion de documents scientifiques de niveau recherche, publiés ou non, émanant des établissements d'enseignement et de recherche français ou étrangers, des laboratoires publics ou privés. 


\section{Accepted Manuscript}

Degradation of gaseous nitriding of steel by lubricant contamination - Effect of in-situ pre-treatments

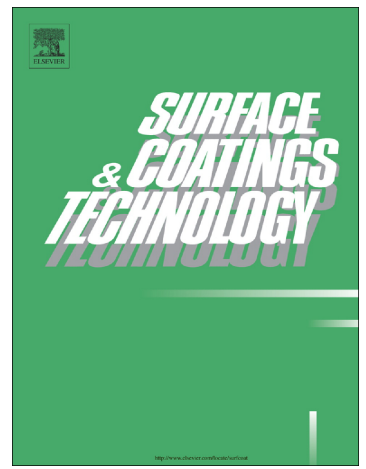

B. Guillot, S. Jégou, L. Barrallier

PII: S0257-8972(17)30127-5

DOI: doi: 10.1016/j.surfcoat.2017.01.107

Reference: SCT 22083

To appear in: $\quad$ Surface \& Coatings Technology

Received date: $\quad 16$ November 2016

Revised date: 29 January 2017

Accepted date: $\quad 30$ January 2017

Please cite this article as: B. Guillot, S. Jégou, L. Barrallier, Degradation of gaseous nitriding of steel by lubricant contamination - Effect of in-situ pre-treatments. The address for the corresponding author was captured as affiliation for all authors. Please check if appropriate. Sct(2017), doi: 10.1016/j.surfcoat.2017.01.107

This is a PDF file of an unedited manuscript that has been accepted for publication. As a service to our customers we are providing this early version of the manuscript. The manuscript will undergo copyediting, typesetting, and review of the resulting proof before it is published in its final form. Please note that during the production process errors may be discovered which could affect the content, and all legal disclaimers that apply to the journal pertain. 


\section{Degradation of gaseous nitriding of steel by lubricant contamination - Effect of in-situ pre-treatments}

B. Guillot, S. Jégou, L. Barrallier

- Benjamin GUILLOT, benjamin.guillot $42 @$ hotmail.fr +33688926501

- Sébastien JEGOU, Lecturer, sebastien.jegou@ensam.eu +33784550984

- Laurent BARRALLIER, Professor of University, Director of the MSMP Lab laurent.barrallier@ensam.eu +33635354626

- Address of the laboratory (Permanent address, for all authors): 2, cours des Arts et Métiers, 13617 Aix-en-Provence FRANCE

\section{Key-words:}

- Gaseous nitriding

- Steel

- Catalytic deactivation

- In-situ treatment

- Pre-oxidation

- Ammonium Chloride 


\section{Abstract}

The present work focuses on the industrial inhibition of gaseous nitrided parts and on the industrial in-situ pre-treatment that can be used to avoid these inhibitions. The first objective is to obtain a repeatable defective nitriding process on carbon iron-based alloys, while the second is to determine the ability of determined in-situ pre-treatments to counter the previously mastered inhibition. Machining oil is used in order to obtain an industrially consistent inhibition. Its presence before chemical treatment strongly inhibits the adsorption of nitrogen atoms at the other surface, leading to heterogeneous nitriding properties of the treated samples. EDS analysis of oil residues indicates the presence of several elements, such as sulphur and carbon. As several studies already focused on the influence of sulphur on nitriding properties, experimentations on the influence of carbon are detailed. Contamination by carbon deposit leads to similar inhibition as in the case of a machining oil contamination. Literature analyses lead to the determination of three in-situ pre-treatments, namely urea $\left(\mathrm{CH}_{4} \mathrm{~N}_{2} \mathrm{O}\right)$, pre-oxidation and ammonium chloride $\left(\mathrm{NH}_{4} \mathrm{Cl}\right)$, to counter the detrimental effects such contaminations. Although all the processes enable to suppress the nitriding inhibition due to the presence of machining oil, ammonium chloride indicates the best capability to activate the adsorption of nitrogen of machining oil contaminated surfaces. 


\section{Introduction}

Thermochemical surface treatments of steels, such as nitriding or carburizing, are of high importance in industry. Gaseous nitriding is known to generate residual stress and hardness gradients at the surface of the treated parts, up to $1 \mathrm{~mm}$ in depth for long treatments [1]. It consists in heating between 450 and $590{ }^{\circ} \mathrm{C}$ a carbon iron-based alloy in a nitrogen-rich atmosphere, for a duration varying between 50 and a few hundredth hours. The ammonia molecule $\mathrm{NH}_{3}{ }^{\mathrm{g}}$ is submitted to a catalytic decomposition phenomenon, leading to the adsorption of atomic nitrogen $\mathrm{N}^{\text {ads }}$ at the iron surface and the formation of gaseous hydrogen $\mathrm{H}_{2}{ }^{\mathrm{g}}[2-4]$.

$$
\mathrm{NH}_{3}{ }^{\mathrm{g}} \rightarrow \mathrm{N}^{\text {ads }}+\frac{3}{2} \mathrm{H}_{2}{ }^{\mathrm{g}}
$$

The increase in nitrogen surface concentration leads to the diffusion of this element to the core of the treated parts [5] and the formation of a nitrided layer that can be dissociated in two parts, depending on the nitriding parameters. At the surface of the sample, a compound layer composed of $\varepsilon-\mathrm{Fe}_{2-3} \mathrm{~N}$ and/or $\gamma^{\prime}-\mathrm{Fe}_{4} \mathrm{~N}$ can develop [6], followed by a so-called diffusion layer composed of a tempered martensitic (ferritic with carbides) matrix with interstitially dissolved nitrogen, cementite at grain boundaries and finely dispersed alloying elements nitrides $\mathrm{MN}$ $(\mathrm{M}=\mathrm{Cr}, \mathrm{Mo}, \mathrm{V}, \ldots)[7]$.

Before nitriding, parts are submitted to different industrial processes, notably in order to give the parts their final shape. These steps can strongly alter the surface state of the parts, being potentially detrimental for the nitriding process. The surface state can be distinguished in two kinds, namely the mechanical state and the physical and chemical state. The first can be altered by rough machining and mechanical surface treatments and can lead to a modification of both precipitation [8-9] and diffusion kinetics [10]. However, it should be emphasised that non-negligible modifications are enabled by extremely high deformation rates, such as $80 \%$, 
generally obtained by cold-rolling [11]. Also, it doesn't seem that this state enables to obtain an industrially non-conforming nitrided part.

Physical and chemical states of a surface also impact the catalytic properties of the substrate and can even reach the total inhibition of the catalytically based reactions [12]. These substrate alterations can modify the nitriding phenomenon and potentially lead to industrial nonconforming parts after treatment. The deactivation of treated surfaces has different origins, such as poisoning or fooling and can be generated during machining, stocking or different treatments applied to the parts before the nitriding treatment. Poisoning is due to a particle, which is easily and strongly adsorbed at the surface of the catalyst, leading to the blocking of the active sites, or in some case, a modification of the electric adsorption properties of the surface. In the case of iron, Maxted et al. reported that poisons are elements of group 5A (N, $\mathrm{P}, \mathrm{As}, \mathrm{Sb})$ and $6 \mathrm{~A}(\mathrm{O}, \mathrm{S}, \mathrm{Se}, \mathrm{Te})[13]$. In the case of nitriding of steels, sulphur, that can be present in machining oils or lubricants, is known to strongly impact the adsorption of nitrogen atoms at the surface of iron [14-15]. Fouling of the catalytic element, which consists in a physical blocking of the active sites, mostly by carbon-based particles, prevents the contact between the catalyst and other elements of the transformation [16]. The carbon particles are generally due to the catalytic dehydrogenation of high molecular weight hydrocarbons. No work on the influence of carbon presence at the surface of parts before nitriding has been found.

In order to counter all these sources of pollution and guarantee the reliability and quality of the nitriding process, several pre-treatments are industrially used. Some are reported to increase the nitriding kinetics, while others are used to counter the detrimental effect of a potentially degraded surface as introduced in the previous paragraph. Treatments can be group in three categories: physical and mechanical, liquid and finally, gaseous treatments. 
Physical and mechanical treatments that affect in-depth the material before nitriding, concern mainly cathode sputtering and shot peening respectively. Baranowska et al. showed that cathode sputtering, before $3 \mathrm{~h}$ nitriding of pure iron, enables to strongly increase the compound layer thickness [17]. It was shown on low alloyed steel that a mechanical pretreatment, inducing nanostructured surface induced by plastic deformation can involve an increase of diffusion kinetics in the case of a nitriding treatment of $15 \mathrm{~h}$ [18]. However, it must be considered that these results are obtained for short durations of treatments. The impact of such pre-treatment on the nitriding properties could be negligible for industrial durations of hundredth of hours.

Liquid treatments consist mainly in washing, dipping and rinsing the parts with specific, chemically controlled products. Birky compared the efficiency of several pre-treatments applied before few hours of gaseous nitriding of two steel grades [19]. Chemical multi-stage washing of samples enabled a faster and more homogeneous compound layer formation. If this preparation improves the reliability of the treatment, no results indicates higher nitriding properties than the reference. The misuse of these processes can lead to the presence of residues at the surface of parts, leading to a potential inhibition of the nitriding. Haase studied the impact of several surface cleaner builders on the nitrogen concentration after a defined nitriding process [20]. The presence of residues generated by some of these products, such as sodium metasilicate $\mathrm{Na}_{2} \mathrm{O}_{3} \mathrm{Si}$ or borax $\mathrm{Na}_{2} \mathrm{~B}_{4} \mathrm{O}_{7} \cdot 10 \mathrm{H}_{2} \mathrm{O}$, leads to a strong reduction of the adsorption of nitrogen. It was also shown that rinsing a part is essential in order to limit the presence of residues and to obtain conforming nitriding properties [21].

The in-situ gaseous activating processes show a growing interest in the nitriding applications [22]. These processes, enabling the surface preparation of the parts in the nitriding oven, strongly limit the potential sources of contamination between the activation and the final nitriding process, increasing its reliability. It consists in activating the surface by 
a direct contact between the surface and a gas at temperatures lower than the nitriding process. The gas can come from solid species at room temperature that generates an activating gas under thermal decomposition.

One of the most common in-situ pre-treatment is pre-oxidation. Friehling et al. shows that this process reduces the incubation time of nitride nucleation [23]. Two hypotheses on the nature of this impact have been settled in another work. One suggests that the presence of an iron oxide layer influences the nitride nucleation while the other suggests that the presence of this layer inhibits the desorption or nitrogen during the catalytic decomposition of ammonia, leading to a higher amount of nitrogen at the surface. Pre-oxidation also modifies the iron nitride nucleation localization from grain boundaries to homogeneously on the whole surface. This enhanced nucleation is explained by an accelerated dissociation of $\mathrm{NH}_{3}$ at the surface of the samples. Irretier et al. studied the impact of surface pollution, such as molybdenum sulphide MoS, iron phosphate $\mathrm{FePO}_{4} \cdot\left(\mathrm{H}_{2} \mathrm{O}\right)_{2}$ or $\mathrm{Fe}_{3}\left(\mathrm{PO}_{4}\right)_{2}$, machining oil, neutral cleaner and alkaline cleaner and of a pre-oxidation treatment on the surface hardness of different steel grades, including $42 \mathrm{CrMo} 4$, after $4 \mathrm{~h}$ of nitriding [24]. The impact of the pre-treatment varies according to the contaminant nature, and in the case of machining oil, $30 \mathrm{~min}$ of pre-oxidation had an even higher detrimental effect on final surface hardness.

The second kind of in-situ pre-treatments is often referred as solid preparation. These are carried out by placing the solid-reactant in the nitriding oven, generating a gaseous product during its thermal decomposition. A patent filed by Christiansen et al. indicates the consistence of this kind of pre-treatments in the case of nitriding [25]. The patent establishes a list of the employable products, including urea $\mathrm{CH}_{4} \mathrm{~N}_{2} \mathrm{O}$ and indicates that this kind of pretreatments enables to nitride stainless steels but also low-alloyed steel with a surface contaminated with lubricant residues or severely deformed by a rough machining. It establishes a minimal temperature, in order to obtain the right decomposition product of, at 
least, $350{ }^{\circ} \mathrm{C}$. The time is expected to be long enough to enable the treatment of the whole surface. In order to determinate the potential product responsible for the surface activation, it is necessary to study the thermal decomposition of this product. The work lead by Schaber et al. on this subject indicates complex decomposition and re-composition [26]. However, at $350{ }^{\circ} \mathrm{C}$, for long enough treatments, every solid product totally decomposes into gaseous species. Amongst these, cyanic acid $\mathrm{HNCO}$ is formed, starting at $350{ }^{\circ} \mathrm{C}$ and reaching a maximum of concentration around $400{ }^{\circ} \mathrm{C}$. It is expected that this substance is responsible for the surface activation.

A patent filed by the company Parker Netsushori Kogyo indicates the possibility to prepare surfaces before nitriding by using ammonium chloride $\mathrm{NH}_{4} \mathrm{Cl}$ [27]. The thermal decomposition of this product leads to the formation of gaseous hydrogen chloride $\mathrm{HCl}$ and ammonia $\mathrm{NH}_{3}$. The hydrogen chloride is expected to chemically attack the surface, leading to the decomposition of a potentially contaminated layer. While the first product enables the activation of surface, the presence of ammonia can lead to its adsorption and the potential formation of a white layer before the nitriding treatment, generating a protection against eventual detrimental oxidation of the surface.

The most common sources of industrial nitriding inhibitions are the poisoning adsorption of specific species, namely sulphur, or an inhibition by the physical presence of carbon at the surface of the parts. In order to counter these defects, surface activation processes are industrially used. While mechanical and liquid preparation are known and widely used, few results have been found concerning the surface activation potential of gaseous pre-treatments. The present work focuses on the ability of three in-situ gaseous pre-treatments, namely preoxidation, urea and ammonium chloride, to activate the surface of industrially machined samples with several degrees of water-dissolved machining oil lubricants. 


\section{Experimental procedure}

\subsection{Material}

Samples $\left(17 \times 13 \times 5 \mathrm{~mm}^{3}\right)$ are manufactured from a 33CrMoV12-9 grade steel, austenitized at $920{ }^{\circ} \mathrm{C}$ for $90 \mathrm{~min}$ followed by a quenching and tempering at $640{ }^{\circ} \mathrm{C}$ under nitrogen atmosphere in order to have a tempered martensite material. The chemical composition, analysed by spark emission spectrometry (SPECTROMAXx MX5M BT from SPECTRO), is provided in Table I. Before any treatments, samples are degreased, rinsed in water and dried in alcohol. This state is referred in the rest of the study as the reference state.

\subsection{Nitriding}

Nitriding is carried out using a SETSYS Evolution thermogravimetric analyser from SETARAM Instrumentations. The atmosphere is composed of a mixture of ammonia, hydrogen and nitrogen $\left(200 \mathrm{~mL} \cdot \mathrm{min}^{-1}\right)$. The temperature is set up at $520{ }^{\circ} \mathrm{C}$, for a nitriding potential of $\mathrm{K}_{\mathrm{N}}=3.7 \mathrm{~atm}^{-1 / 2}$ during $300 \mathrm{~min}$. The duration of treatment is chosen to be low as the impact of the physical and chemical state on the nitriding properties should be decreasing with the nitriding duration. Three vacuums down to $20 \mathrm{~Pa}$ followed by refilling with helium was performed before each treatment. Heating and cooling steps are conducted under an atmosphere of neutral gas, $\mathrm{He}$ and $\mathrm{N}_{2}$, at a rate of $10{ }^{\circ} \mathrm{C} \cdot \mathrm{min}^{-1}$. Mass gain curves are corrected from fluid dynamics using a copper covered sample under the same treatment conditions.

\subsection{Material characterization}

After nitriding, samples are grinded and polished down to a $0.5 \mu \mathrm{m}$ diamond solution and cleaned by ultrasound during $3 \mathrm{~min}$ before being etched with a $2 \%$-nital solution $(2 \mathrm{~mL}$ of nitric acid $\mathrm{HNO}_{3}$ in $98 \mathrm{~mL}$ of ethanol $\mathrm{C}_{2} \mathrm{H}_{6} \mathrm{O}$ ). Microstructure observations are carried out under an Olympus BX41M optical microscope equipped with a PixelLink camera and a JEOL JSM 7001F FEG scanning electron microscope (SEM) using a $15 \mathrm{kV}$ acceleration 
voltage. Hardness profiles were obtained using a LEICA VMHT device with a load of $1.9 \mathrm{~N}$ applied during $15 \mathrm{~s}$. The effective depth of nitrided layers is defined as the depth for which the hardness value is equal to the bulk hardness plus $100 \mathrm{HV} 0.2$ [28]. The chemical composition is analysed by a SPECTROMAXx MX5M BT spark optical emission spectrometer from SPECTRO, Amtek. Depth profiling is obtained by successive mechanical grinding until elimination of previous sparks. Layer removal was controlled by dial indicator. Profiles are obtained from four measurements at different locations of one side of samples.

\subsection{Oil-based contamination}

Contamination is carried out using a BLASOCUT BC 935 Kombi machining oil from Blaser Swisslube. Although the chemical composition is not fully known, the product is composed of phenoxypropanol $\mathrm{C}_{9} \mathrm{H}_{12} \mathrm{O}_{2}$, petroleum sulfonates, sodium salts and carboxylic acid ether.

Samples were soaked in a mixture of machining oil and water. The machining oil is dissolved in water at different ratio. Several ratios were studied in this part of the work, namely 1, 5 and $25 \%$. After 1 min of soaking, samples are taken out from oil bathing and droplets of oil at the surface are manually removed using an absorbing paper. Samples are then immediately placed in the thermogravimetric analyser for thermochemical treatments.

\subsection{Carbon deposition}

In order to study the influence of the presence of carbon on the treated surface, carbon deposition was performed on a sample under a vacuum bell using a heated carbon wire heated by joule effect. Considering the time of the experimentation, the carbon layer thickness on the facing side can be estimated between 300 and $500 \mathrm{~nm}$. On the opposite face, it is expected that no or little carbon is deposited.

\subsection{Pre-treatments}


Pre-oxidation was carried out in the thermogravimetric analyser. The vacuum procedure proposed in the nitriding section is applied before the pre-oxidation treatment in order to avoid unwanted oxidation from residual air. Pre-oxidation is carried out at a fixed temperature of $350{ }^{\circ} \mathrm{C}$ during $1 \mathrm{~h}$. The atmosphere is composed of pure oxygen at a rate of $30 \mathrm{~mL} \cdot \mathrm{min}^{-1}$ mixed with helium at a rate of $200 \mathrm{~mL} \cdot \mathrm{min}^{-1}$. After oxidation, sample is cooled to room temperature under inert gas in order to visually control its aspect. The pre-treatment, if correctly carried out, generates a layer of iron oxides at the surface of the part, leading to a blue aspect of the overall surface. As a direct consequence, an optical observation of the surface before nitriding gives qualitative information on the quality and homogeneity of the pre-treatment.

Urea and ammonium chloride used were pure at $99.0 \%$ and are solid at room temperature. A mass of $200 \mathrm{mg}$ of products is introduced with the treated sample in an atmosphere controlled oven (HM70 from Pyrox). Pre-treatments are carried out at $400{ }^{\circ} \mathrm{C}$ during 100 min under inert gaseous nitrogen $\mathrm{N}_{2}$ in order to prevent the sample from oxidation during heating. Heating and cooling of the sample are carried out at $10{ }^{\circ} \mathrm{C} \cdot \mathrm{min}^{-1}$ under inert gas $\mathrm{N}_{2}$. After cooling down to room temperature, samples are immediately introduced in the thermogravimetric analyser in order to be nitrided.

\section{Results}

\subsection{The reference state}

The mass gain, obtained by thermogravimetric analysis, of the sample is presented in Fig. 1. This experimentation was carried out several times in order to study the variability of the experiment. The mean value of final mass gain is $1.49 \pm 0.03 \mathrm{mg} . \mathrm{cm}^{-2}$. The results also show important nitriding kinetics during the first hours of the treatment. After nitriding, the sample showed a homogeneous light grey matt surface. Observation of the microstructure reveals a compound layer, with a mean thickness value of $9 \pm 0.9 \mu \mathrm{m}$, followed by a diffusion zone 
(Fig. 2A). Hardness measurements are given in Fig. 3. The hardness profile shows a surface hardness value of $940 \mathrm{HV} 0.2$ at $40 \mu \mathrm{m}$ and an effective depth of $135 \mu \mathrm{m}$. The nitrogen and carbon in-depth composition profiles are given in Fig. 4. After $5 \mathrm{~h}$ of nitriding at $520^{\circ} \mathrm{C}$, the nitrogen profile is characterized by a smooth transition from 1.2 wt. $\%$ at the compound/diffusion interface to the un-nitrided core material. A decarburization of the nitrided surface and an enrichment of carbon in front of the diffusion front are also observed. The occurring of this phenomenon during gaseous nitriding of low-alloyed steels is known and was already characterised [29].

\subsection{Influence of cutting oil contamination}

The mass gain profiles obtained during nitriding of two oil contaminated samples ( 1 and $5 \%$ ) are provided in Fig. 1. The $1 \%$-contaminated sample has a final mass gain of $0.72 \mathrm{mg} . \mathrm{cm}^{-2}$, while the $5 \%$-contaminated sample has a very low final mass gain of $0.14 \mathrm{mg} . \mathrm{cm}^{-2}$. The mass gain curves are also spread over time indicating a strong impact of oil residues on the kinetics of nitriding. The nitriding of a $1 \%$-contaminated sample has been carried out 4 times, leading to a final mass gain of $0.67 \pm 0.10 \mathrm{mg} . \mathrm{cm}^{-2}$. Contrary to the relatively low variability of the mass gain profiles obtained during the nitriding of reference samples, the nitriding of samples contaminated by $1 \%$ of oil leads to a higher variability, that can be assigned to the heterogeneity of the film of water-dissolved oil at the surface of samples. In facts, the surface tension of the sample leads to the presence of oil in the shape of drops of various sizes. Fig. 5 provides a macrograph of the two large faces of the $1 \%$ oiled sample after $5 \mathrm{~h}$ nitriding at $520{ }^{\circ} \mathrm{C}$. The observation indicates two distinctive aspect of the surface. For most of the sample, the surface shows a matt light grey aspect while the rest of it has a metallic aspect. Observation carried out where the aspect of the sample is matt light grey (P1 in Fig. 5) indicates the presence of a thin white layer. Its thickness is more than 3 times lower than the reference sample(s) $\left(2.7\right.$ and $9 \mu \mathrm{m}$ respectively) after $5 \mathrm{~h}$ of nitriding at $520{ }^{\circ} \mathrm{C}$. 
Microstructural observations carried at point P2 of the $1 \%$ oil-contaminated sample are provided in Fig. 2B. The aspect did not change at this point after nitriding (P2 in Fig. 5), and corresponds to either an un-nitrided zone or to a zone where a diffusion layer is present without a compound layer.

Microhardness measurements (Fig. 3) were carried out at the two different locations on the $1 \%$-oiled sample indicated by P1 and P2 in Fig. 5. Locations were chosen according to their macroscopic appearance from dark to bright grey matt that leads to the assumption of different kinetics of nitriding. Hardness profiles show that the nitrided surface is characterized by different effective depths (130 and $75 \mu \mathrm{m}$ for $\mathrm{P} 1$ and $\mathrm{P} 2$ respectively). It confirms the heterogeneous nitriding of the treated surface due to the presence of a non-uniform film of oil. The superficial hardness is however not modified in the present cases. This suggests a similar enrichment of nitrogen in the diffusion zone or the presence of a compound layer at a different stage of growth.

Finally, OES analyses (Fig. 6) have been carried out at the two points A and B, indicated in Fig. 5. Due to the heterogeneity of the sample, no variability is presented. These two zones are respectively characterized by a heterogeneous metallic and matt aspect and a homogeneous matt aspect that refers to nonconforming and conforming nitrided zones respectively. Chemical composition profiles are in agreements with previous observations. Zone B (homogeneous aspect) exhibits a nitrogen in-depth profiles similar to the reference after $5 \mathrm{~h}$ of nitriding at $520^{\circ} \mathrm{C}$ whereas the progress of nitrogen enrichment in the zone with a heterogeneous aspect (point A) is less important, in terms of surface value and of affected depth.

Increasing the fraction of oil from 1 to $5 \%$ in water tends to fully hinder the kinetics of nitriding. The final mass gain only reaches $0.14 \mathrm{mg} . \mathrm{cm}^{-2}$ after $5 \mathrm{~h}$ at $520^{\circ} \mathrm{C}$ (Fig. 1). The 
global aspect of the sample after nitriding is unchanged, which indicates that almost no white layer was formed at the surface of the part. Light microscope observations after nitriding showed no compound layer formed and almost no modification of the initial microstructure on the whole sample. Microhardness measurements carried at several points of the sample confirmed the hinder of nitriding with a surface hardness $(50 \mu \mathrm{m}$ below the surface) that reaches only $400 \mathrm{HV} 0.2$ after $5 \mathrm{~h}$ of nitriding against $930 \mathrm{HV} 0.2$ for the reference state (Fig. 3).

\subsection{Influence of a carbon deposition on nitriding}

This section focuses on the analysis of machining oil residues generated at nitriding temperatures. Before experimentation, the sample was submitted to polishing down to a $0.5 \mu \mathrm{m}$ diamond solution and cleaned by ultrasound during $3 \mathrm{~min}$ before dipping, in order to dissociate oil residues from machining chips. After dipping in a $1 \%$ oil-water solution, the surplus of solution was manually removed with an absorbing paper. Following an isothermal treatment at $350{ }^{\circ} \mathrm{C}$ during $1 \mathrm{~h}$, the surface of the sample was observed with SEM and backscattered electrons. The sample is characterized by small particles of 1 to $5 \mu \mathrm{m}$ diameters, dispersed regularly at the surface (Fig. 7). According to EDS analysis as compared to the reference zone, the observed particles are mainly composed of carbon, but also oxygen, calcium and silicon (Fig. 8). Sulphur, oxygen and calcium are also present in the surrounding.

As several studies over the influence of sulphur on nitriding have been found in the literature, this work focuses on the influence of a pure carbon deposit. A sample was nitrided after being submitted to a carbon deposition process, as detailed in part 2.4. The nitriding kinetics during the two first hours is slower and the final mass gain $\left(0.58 \mathrm{mg} \cdot \mathrm{cm}^{-2}\right)$ is nearly three times lower than the reference that reaches $1.49 \mathrm{mg} \cdot \mathrm{cm}^{-2}$ (Fig. 9). The two sides of the sample have a very heterogeneous appearance after nitriding. The exposed face (facing the carbon wire during deposition prior to nitriding) indicates mostly a metallic aspect (Point C, Fig. 10). A few areas 
with a matt light grey aspect appear at the bottom of the part (Point A, Fig. 10). The microstructural observation of the exposed face indicates that a very thin compound layer is present in the zones where a matt grey aspect is present (Fig. 11A, corresponding to observation at point $\mathrm{A}$ in Fig. 10). The white layer reaches a thickness of $2.5 \mu \mathrm{m}$. In the zone where a metallic aspect can be observed, a diffusion layer is observed without a compound layer (Fig. 11B, corresponding to observation at point $\mathrm{C}$ in Fig. 12). The presence of carbon at the surface seems detrimental for the nitriding process. This observation is confirmed by microhardness measurements, carried out at several points of the exposed face (Fig. 10). Measurements carried out at points where a thick compound layer is present (Point A, Fig. 10) indicates hardness values at $50 \mu \mathrm{m}$ of $890 \mathrm{HV} \mathrm{0.2,} \mathrm{which} \mathrm{is} \mathrm{close} \mathrm{to} \mathrm{the} \mathrm{reference.} \mathrm{However,}$ measurements carried out at points where a thin, or no compound layer could be observed indicates a strongly diminished hardness value at $50 \mu \mathrm{m}$ (Point C, Fig. 10).

\subsection{Pre-oxidation and machining oil}

Figure 12 gives the mass gain during nitriding of a reference sample, submitted to preoxidation before nitriding. It indicates lower kinetics of nitriding after pre-oxidation. After five hours of treatment, the final mass gain of this sample reaches $1.34 \mathrm{mg} . \mathrm{cm}^{-2}$ which is $0.15 \mathrm{mg} . \mathrm{cm}^{-2}$ lower to the reference. The sample had a homogeneous matt light grey aspect on the whole surface. The microstructure observations and microhardness measurements exhibit very little difference with the reference sample. The nitrided surface is, as a consequence, very similar to the reference one and the results suggest that the delay in the kinetics of nitriding observed in Fig. 12 corresponds to the initial presence of an oxide layer due to preoxidation.

Pre-oxidation was carried out on samples immersed in machining oil water diluted at different degrees: $1 \%, 5 \%, 25 \%$ and pure oil. The corresponding mass gain profiles during nitriding are provided in Fig. 13. Pre-oxidation considerably increase the kinetics of nitriding of oil- 
contaminated samples. Detrimental effects of 1 and $5 \%$ oil solutions on nitriding are almost entirely suppressed after pre-oxidation. Microstructure observations of the $1 \%$-contaminated sample indicate a homogeneous white layer, slightly thinner than the reference. Microhardness measurements of the $1 \%$-contaminated sample indicate a mean surface hardness of $900 \mathrm{HV}$ 0.2. This value is very close to the reference sample. The effective depth is equal to $135 \mu \mathrm{m}$ as for the reference. For the $5 \%$-contaminated sample pre-oxidised, the microstructure observations show a thick white layer (Fig. 14A), similar as for the $1 \%$ contaminated treated with pre-oxidation. Hardness measurements show that the surface hardness reaches $875 \mathrm{HV} 0.2$, which is almost the same as the reference and that the effective depth reaches $125 \mu \mathrm{m}$, which is lower than the reference (Fig. 15).

\subsection{Pre-oxidation and carbon deposition}

Pre-oxidation was tested on carbon deposition prior to nitriding. The mass gain curve clearly indicates that the surface with a carbon deposition was activated by pre-oxidation (Fig. 9). While the carbon-contaminated samples had a final mass gain of $0.58 \mathrm{mg} . \mathrm{cm}^{-2}$, the pre-treated sample reached a final mass gain of $1.49 \mathrm{mg} . \mathrm{cm}^{-2}$, similar to the reference. Macroscopic observation of the samples after treatment shows a homogeneous matt grey layer. Microstructure observations indicate a similar nitrided surface to the reference with a white layer thickness of $9 \mu \mathrm{m}$ (Fig. 14B). Microhardness in-depth profiles are given in Fig. 16, for the exposed side of the sample. Surface hardness reaches 870 HV0.2 for this face. The nitriding depth is equal to $145 \mu \mathrm{m}$, which is higher than the reference $(135 \mu \mathrm{m})$.

\subsection{Urea}

Surface preparation by urea and $\mathrm{NH}_{4} \mathrm{Cl}$ were investigated in the case of nitriding of steels contaminated with machining oil and compared to pre-oxidation. The impact of a preparation using urea on mass gain kinetics is given in Fig. 17. Urea preparation involves slightly lower kinetics of nitriding during the first hours as compared to the reference. However, the final 
mass gain reaches $1.45 \mathrm{mg} . \mathrm{cm}^{-2}$, which is lower but close to the reference $\left(1.49 \mathrm{mg} . \mathrm{cm}^{-2}\right)$. Urea pre-treatment on a $1 \%$ oil-contaminated sample leads to a final mass gain per surface of $1.43 \mathrm{mg} . \mathrm{cm}^{-2}$. Thermogravimetric analyses of samples contaminated by a $5 \%$ oil solution and prepared with urea indicate a final mass gain of $1.36 \mathrm{mg} \cdot \mathrm{cm}^{-2}$ while the sample without preparation barely reached $0.14 \mathrm{mg} . \mathrm{cm}^{-2}$. The corresponding microhardness measurements are given in Fig. 18. The hardness at $50 \mu \mathrm{m}$ reaches 860 and $870 \mathrm{HV} 0.2$ for 1 and $5 \%$ waterdissolved oil, and the effective depth reaches 135 and $120 \mu \mathrm{m}$ respectively.

The preparation with urea also had a significant effect on contaminations by $25 \%$ of oil. The final mass gain per surface reached $0.68 \mathrm{mg} \cdot \mathrm{cm}^{-2}$. This value is lower than the reference but higher than the final mass gain of the sample contaminated by $5 \%$ of oil, nitrided without preparation process. However, it is lower than the one obtained by a pre-oxidation in similar conditions $\left(1.25 \mathrm{mg} . \mathrm{cm}^{-2}\right)$. The sample contaminated with $25 \%$ of oil and prepared under urea showed a very thin white layer, with a few locations where it could not be observed, in agreement with the mass gain curve. The mechanical properties of the sample contaminated with $25 \%$ of oil and prepared under urea are lower, in terms of surface hardness and nitriding depth, than the reference (Fig. 18).

\section{7 $\mathrm{NH}_{4} \mathrm{Cl}$}

The thermogravimetric analyses carried out over the reference sample and samples contaminated with oil and prepared with ammonium chloride are provided in Fig. 19. No reduction of the nitriding kinetics could be observed after applying this pre-treatment to the reference sample. The final mass gain is $1.49 \mathrm{mg} . \mathrm{cm}^{-2}$, which is equal to the reference. The hardness at $50 \mu \mathrm{m}$ reaches $900 \mathrm{HV} 0.2$ and the effective depth is $140 \mu \mathrm{m}$ (Fig. 20).

The final mass gains of samples prepared with ammonium chloride after a $5 \%$ and $25 \%$ oilcontamination reach 1.49 and $1.39 \mathrm{mg} . \mathrm{cm}^{-2}$, indicating a strong surface activation potential of 
the considered product (Fig. 19). Hardness-depth profiles of these samples are indicated in Fig. 20. Hardness at $50 \mu \mathrm{m}$ of all the samples contaminated by different degrees of oil dilution and prepared with ammonium chloride are close to the reference. The samples contaminated by 5 and $25 \%$ have a hardness at $50 \mu \mathrm{m}$ of 920 and $880 \mathrm{HV} 0.2$ respectively. The effective depths of the 5 and $25 \%$ samples reach $140 \mu \mathrm{m}$, which is slightly higher than the reference, but equal to the reference sample prepared under oxygen.

\section{Discussion}

The impact of a machining oil film on the nitriding properties is non-negligible. While the considered product is industrially used at a $8 \%$ rate, a $1 \%$ oil film strongly inhibits the nitriding properties. This is confirmed by observing the final mass gain, that are divided by 2 after $5 \mathrm{~h}$ of nitriding at $520{ }^{\circ} \mathrm{C}$ and $\mathrm{K}_{\mathrm{N}}=3.7 \mathrm{~atm}^{-1 / 2}$ (Tab. II) and the strong reduction of mechanical properties (Tab. III). Even if the industrial parts are highly cleaned before nitriding, and are thus theoretically free from oil residues, their complex shapes can lead to a detrimental surface preparation. In the case of nitriding of an oil-contaminated sample, the variability of the final mass gain measure is high and can be attributed to the heterogeneity of the oil film obtained by immersion. The variability of $1 \%$ contaminated and nitrided samples remains low enough, compared to the diminishing of final mass gain, for not being detrimental in the present analysis. Increasing the oil-based contamination indicates that the higher the concentration of oil, the lower the nitriding kinetics is. This result is not in agreement with the work done by Irretier et al., where a contamination by residues of machining oil had no significant impact on the nitriding properties generated after a $4 \mathrm{~h}$ nitriding at $520{ }^{\circ} \mathrm{C}$ and $\mathrm{K}_{\mathrm{N}}=10 \mathrm{~atm}^{-1 / 2}$ [24]. However, the criterion of evaluation of the nitriding quality was chosen to be the surface hardness. It has been shown in the present work 
that the surface hardness is not sufficient in order to estimate the quality of nitriding. In Fig. 3, it can be observed that the values of surface hardness are the same for several areas of the sample but in-depth profiles vary leading to non-compliant nitriding depth.

The nature of the industrial oil used is also a source of difference with the literature due to the complex chemical composition of oils. Precautions must be taken during comparisons. The reduction of nitriding kinetics is due to machining oil residues at the surface of parts. After isothermal treatment at $350{ }^{\circ} \mathrm{C}$ of a sample immersed in water-dissolved oil, SEM characterizations of the surface mainly indicate the presence of oxide, silicon, calcium, sulphur and carbon compounds in these residues. The inhibition of catalysis properties by sulphur poisoning is a much studied phenomenon. Only a low amount of sulphur concentration can dramatically lower the catalytic properties [14-15]. In the present study, the effect of a carbon deposition on nitriding was shown to also have a strong and detrimental influence on the nitriding kinetics. The deactivation of catalytic properties of steels by the presence of an oil film can then be expected from the carbon residues on the treated surface. During heating to nitriding temperature, most of the oil film is burnt. Hawkins makes the distinction between three kinds of carbon deposits [16]. The firsts are fine and loose carbons, generally generated by dehydrogenation of carbon-containing gas, and are easily removed by oxidation in air. The seconds are resinous polymeric like carbons due to the dehydrogenation of high molecular weight compounds, such as alkanes and naphthenes. These two first categories are expected to be burnt in air at temperatures from $300{ }^{\circ} \mathrm{C}$. If not, heating will induce the formation of graphitic carbon (the third kind of carbon deposit) that regroups dehydrogenation of single aromatic rings hydrocarbons, such as benzene, leading to multiring, graphitic form polymers that cannot be removed by air oxidation. It is not expected to burn in air at temperatures below $580{ }^{\circ} \mathrm{C}$. In the case of the experimentations lead in this work, the burning of oil by heating at nitriding temperatures generates residues of carbon of 
the third kind, leading to a local complete inhibition of catalytic properties. SEM-observations indicated that these residues are homogeneously spread out all over the surface, locally inhibiting the catalytic deactivation. At the locations where the surface is clean from residues, nitriding occurs as in the reference case. As a consequence, for contaminated samples, the effective surface is reduced, leading to an inhibited global amount of nitrogen adsorption during the process. If the contamination is high enough, the inhibition of nitrogen adsorption can lead to the prevention of the compound layer formation.

Three surface in-situ preparations were investigated. Urea and $\mathrm{NH}_{4} \mathrm{Cl}$ were compared to preoxidation prior to nitriding. Their efficiency was tested on samples immersed in waterdissolved oil. Some work has been done over the influence of pre-oxidation before gaseous nitriding. During the present work, it has been carried out over cleaned and contaminated samples. During the pre-treatment of cleaned samples, the early nitriding kinetics observations showed that an incubation time has been settled by the pre-oxidation. It should be considered that the layer formed during pre-oxidation is decomposed during the heating under neutral gas and during the nitriding process. This is expected to happen by the phenomenon of oxide layers reduction that occurs due to the presence of hydrogen. This reduction can generate an incubation time during the nitriding treatment, depending on the thickness of the layer. However, this result is in contradiction with the different results obtained in the literature, indicating that a pre-treatment by oxidation reduces the incubation time already present during the nitriding process [22]. It should be considered that the pretreatment parameters can influence the layer formed. Irretier et al. prepared the samples with a very low partial oxygen pressure $\left(5.710^{-23} \mathrm{~Pa}\right)$ [24], while the oxidation process was carried out, in this work, with a partial oxygen pressure of approximately $1310^{3} \mathrm{~Pa}$. As a consequence, it can be assumed that the layer formed during the present work is thicker than the one obtained in the reference, leading to a non-negligible reduction duration, and so, a 
higher nitriding incubation time. As a reminder, no optimisation of the pre-treatment parameters is carried out during this work.

The work carried out by Irretier et al. also showed that a pre-oxidation of $30 \mathrm{~min}$ in air improved the mechanical properties after nitriding in the case of $42 \mathrm{CrMo} 4$-grade steel, and inhibited these mechanical properties in the case of C15 and X155CrMoV12.1 grade steels [24]. Neither of these results is in agreements with the present work. The considered preoxidation treatment only enabled to negligibly modify the mechanical properties of the treated sample.

On some specific alloys, the pre-oxidation treatment leads to a higher surface hardness for the reference state. This increase can be explained by supposing that the pre-oxidation treatment has an impact on the nitride precipitation, leading to thinner nitrides and as a consequence, higher hardness. It should also be considered that the activity of oxygen at the surface of the solid leads to the diffusion of carbon to the surface, indicating a loss of carbon in the first tenth micrometres of the substrate and a modification of nitriding properties.

Also, it should not be forgotten that the results presented by Irretier et al. shows that the pretreatment is very sensitive to the steel grade considered. The difference in chemical composition, notably in alloying elements, of the considered steels between the two studies could explain this divergence. The oxidation of high-chromium content alloys can lead to the formation of chromium oxide at the surface of parts, being detrimental for the nitriding process. Moreover, it should be considered that the mechanical surface preparation of the reference state is different between the two studies, potentially explaining the divergence of results.

Despite the influence of the thickness of the oxide layer on a reference sample, pre-oxidation has a strong capacity to counter the inhibition generated by machining oil residues. This 
impact can be observed over thermogravimetric analysis but also microstructure observations, hardness and residual stress measurements. While a pollution of $5 \%$ diluted oil almost completely prevents the sample from nitriding, a $1 \mathrm{~h}$ pre-treatment by oxidation lead to a homogeneously nitrided sample, very close from the reference. This capacity to annihilate the degrading impact of oil residues has been confirmed up to a dilution of $25 \%$ of oil in water.

This study stated that the carbonic particles of the machining oil residues might play an important role in the inhibition of nitriding by this kind of pollution. In order to verify this hypothesis, a pre-oxidation treatment (that has a strong impact on machining oil contamination) is applied to a carbon contamination. The results indicate that the use of this pre-treatment enables to remove the inhibiting carbon layer, leading to a nitrided layer similar to the reference. Pre-oxidation involves adsorption of oxygen at the surface of carbon residues leading to the cleaning of the surface by the formation of gaseous compounds, such as $\mathrm{CO}$ or $\mathrm{CO}_{2}$. The fact that the pre-oxidation treatment activates, in a similar way, a surface contaminated by oil and by carbon deposit leads, once again, to the conclusion that the presence of element carbon is a non-negligible reason for the inhibition of nitriding process by an oil-based contamination.

Finally, urea and ammonium chloride have been tested over reference and oil-based contaminations. Their impact on reference state before nitriding indicates no remarkable improvement on the nitriding properties, although the depth of residual stress profiles seems higher. In the case of the preparation of an oil-contaminated surface, both processes showed activating properties. Analyses of samples contaminated by 1 and $5 \%$ oil, and prepared by oxidation, urea or ammonium chloride indicated microstructural and mechanical properties similar to the reference. In order to compare the different processes, the application of pretreatments over a $25 \%$ oil-contaminated sample enables to determine that the ammonium 
chloride provides the higher surface activation capacity. This result can be confirmed by observing the final mass gain (Fig. 21), but also mechanical properties (Tab. III).

The activation properties of urea and ammonium chloride are certainly due to their capacity to generate a chemical etching of the contaminant. This hypothesis could be confirmed by using different methods of surface analysis.

\section{Conclusions}

The present work focuses on the inhibition of the gaseous nitriding process by an industrial contamination, namely machining oil. The results indicated a strong negative influence of this product over the nitriding properties, i.e. nitrogen adsorption, leading to a heterogeneous aspect of the parts and a global lowering of mechanical properties. In addition to the wellknown detrimental effect of sulphur and phosphate, the present work shows that the inhibition of the treated surface can be due to the presence of carbon particles leading to a strong alteration of the catalytic decomposition. The capacity of several in situ pre-treatments to counter this inhibiting effect has been studied. The pre-oxidation treatment has no impact on the nitriding of clean samples, neither in terms of nitriding kinetics nor mechanical properties. It should be reminded that pre-treatment parameters are estimated from literature analysis and that no optimisation of these values is carried out. The pre-treatment proved to counter the inhibiting effect of machining oil-contaminations before nitriding, enabling to reach the reference nitriding properties, even for samples highly contaminated ( $25 \%$ dilution rate). Better results were obtained using ammonium chloride in terms of nitriding kinetics and nitrogen adsorption since no layer (such as iron oxide from pre-oxidation) has to be reduced. The surface activation is expected to happen by decomposition of the contaminants, according to the atmosphere obtained during heating $\left(\mathrm{NH}_{4} \mathrm{Cl}\right.$ decomposes into $\mathrm{NH}_{3}$ and $\left.\mathrm{HCl}\right)$. Although, urea product showed good surface activating properties in the case of low oil dilution rates, its 
ability to counter a machining oil-based contamination proved to be lower than the two previous processes for a rate of $25 \%$.

\section{Acknowledgments}

This research was supported by BPIFrance (grant FUI AAP14-DefiNIT-F1302013U). The authors deeply thank Airbus Helicopters and Bodycote for sample machining and heat treatment. The authors also thank Ch. Dominici (CP2M, Aix-Marseille University) for carbon deposition. 


\section{List of references}

[1] M. Hirsch, Treatment of iron and steel, Patent US 1,772,866 A (1930).

[2] G. Ehrlich, The mechanism of chemisorption on metals, Journal of Physics and Chemistry of Solids 1 (1956) 1-13.

[3] H.J. Grabke, Reaktionen von Ammoniak, Stickstoff und Wasserstoff and der Oberfläche von Eisen, Berichte der Bunsengesellschaft für physikalische Chemie 72 (1968) 533-541.

[4] G. Ertl, M. Huber, Mechanism and Kinetics of Ammonia Decomposition on Iron, Journal of Catalysis 61 (1980) 537-539.

[5] H.C.F. Rozendaal, E.J. Mittemeijer, P.F. Colijn, P.J. van der Schaaf, The development of nitrogen concentration profiles on nitriding iron, Metallurgical Transactions A 14 (1983) 395399.

[6] Y. Inokuti, N. Nishida, N. Ohashi, Formation of $\mathrm{Fe}_{3} \mathrm{~N}, \mathrm{Fe}_{4} \mathrm{~N}$ and $\mathrm{Fe}_{16} \mathrm{~N}_{2}$ on the Surface of Iron, Metallurgical Transactions A 6 (1975) 773-784.

[7] B. Mortimer, P. Grieveson, K.H. Jack, Precipitation of nitrides in ferritic iron alloys containing chromium, Scandinavian Journal of Metallurgy 1 (1972) 203-209.

[8] A. Brahmi, R. Borrelly, Study of aluminium nitride precipitation in pure Fe-Al-N alloy by thermoelectric power measurements, Acta Materialia 45 (1997) 1889-1897.

[9] S.R. Meka, E. Bischoff, S.S. Hosmani, E.J. Mittemeijer, Interrelationships of defects, nitride modification and excess nitrogen in nitrided $\mathrm{Fe}-4.75$ at.\% $\mathrm{Al}$ alloy, International Journal of Materials Research 105 (2014) 1057-1066.

[10] B. Guillot, S. Jégou, L. Barrallier, Influence of strain hardening on gaseous nitriding of steels, Conference proceedings of the $23^{\text {rd }}$ International Federation of Heat Treatments and Surface Engineering Congress, Savannah, United States (2016) 629-635.

[11] M.H. Biglari, C.M. Brakman, E.J. Mittemeijer, S. van der Zwaag, Analysis of the nitrogen absorption isotherms of cold-rolled Fe-2 at.\% Al specimens with different AIN precipitate dimensions, Philosophical magazine A 72 (1995) 931-947.

[12] C.H. Bartholomew, Mechanisms of catalyst deactivation, Applied Catalysis A : General 212 (2001) 17-60.

[13] E.B. Maxted, The poisoning of metallic catalysis, Advances in Catalysis 3 (1951) 129171.

[14] W. Arabczyk, D. Moszynski, U. Narkiewicz, R. Pelka, M. Podsiadly, Poisoning of iron catalyst by sulfur, Catalysis Today 124 (2007) 43-48.

[15] H.J. Grabke, Kinetics of Gas-Solid Interactions, Material science forum 154 (1994) 6986.

[16] G.B. Hawkins, The impact on catalyst performance due to poisoning and fouling mechanisms, Technical report (2013) GBH Entreprises. 
[17] J. Baranowska, K. Szczecinski, M. Wysiecki, Activation of surface in gas nitriding process, Proceedings of the $7^{\text {th }}$ international conference on shot peening. Institute of precision mechanics, Warsaw, Poland, 1999.

[18] S.M. Hassani-Gangaraj, A. Moridi, M. Guagliano, A. Ghidini, M. Boniardi, The effect of nitriding, severe shot peening and their combination on the fatigue behavior and microstructure of a low-alloy steel, International Journal of Fatigue 62 (2013) 1-10.

[19] Z.S. Birky, Optimizing surface activation for repeatable compound layer growth, Proceedings of the $28^{\text {th }}$ ASM heat treating society conference, Detroit, United States (2015) 588-593.

[20] B. Haase, Residue-free surface cleaning prior to heat treatment, Surface Modification Technologies IX, Proceedings of the $9^{\text {th }}$ International Conference on Surface Modification Technologies, Cleveland, USA (1996).

[21] B. Haase, J. Dong, Industrial free cleaning using halogen free cleaning agents : surfactant solutions and hydrocarbon solvents, Surface Engineering 14 (1998) 43-48.

[22] P.B. Friehling, F.W. Poulsen, M.A.J. Somers, Nucleation of iron nitrides during gaseous nitriding of iron; effect of a preoxidation treatment, Zukunft von Metallkunden 92 (2001) 589-595.

[23] P.B. Friehling and M.A.J. Somers, On the effect of preoxidation on nitriding kinetics, Surface Engineering 16, $\mathrm{n}^{\circ} 2$ (2000) 103-106.

[24] O. Irretier, C. Naber, J. Dong, H. Klümper-Westkamp, B. Haase, K. Bauckhage, Influence of contaminants on gas nitriding, Surface Engineering 12 (1996) 331-334.

[25] T.L. Christiansen, T.S. Hummelshoj, M.A.J. Somers, A method of activating an article of passive ferrous or non-ferrous metal prior to carburising, nitriding and/or nitrocarburising, US Patent US8845823 B2 (2010).

[26] P.M. Schaber, J. Colson, S. Higgins, D. Thielen, B. Anspach, J. Brauer, Thermal decomposition (pyrolysis) of urea in an open reaction vessel, Thermochimica Acta 424 (2004) 131142 .

[27] K. Hoshino, M. Miyashita, T. Kawamura, T. Totsuka, H. Eiraku, K. Yashiro, and T. Kurosawa, Method for activating surface of metal member, Patent WO2005068679 A1 (2005).

[28] Standard ISO 4970:1979 Aciers - Détermination de l'épaisseur totale ou conventionnelle des couches minces durcies superficielles.

[29] G. Fallot, Rôle du carbone lors de la nitruration d'aciers de construction et influence sur les propriétés mécaniques, Ph. D Report, Ecole Nationale Supérieure d'Arts et Métiers, Laboratoire MSMP (2015). 


\section{List of figure captions}

Figure 1 - Mass gain profiles of the reference, $1 \%$ and $5 \%$ oil contaminated samples nitrided during $5 \mathrm{~h}$ at $520{ }^{\circ} \mathrm{C}$ and a nitriding potential of $3.7 \mathrm{~atm}^{-1 / 2}$.

Figure 2 - Optical microscope observations (2\%-nital etching) of the reference (A) and at the point P2 (Fig. 5) of the $1 \%$ oil contaminated (B) samples nitrided during $5 \mathrm{~h}$ at $520{ }^{\circ} \mathrm{C}$ and a nitriding potential of $3.7 \mathrm{~atm}^{-1 / 2}$.

Figure 3 - Microhardness profiles of the reference, of two different locations (P1 and P2, Fig. 5) of the $1 \%$ oil-contaminated and of the $5 \%$ oil-contaminated samples nitrided during $5 \mathrm{~h}$ at $520{ }^{\circ} \mathrm{C}$ and a nitriding potential of $3.7 \mathrm{~atm}^{-1 / 2}$.

Figure 4 - Nitrogen and Carbon content of the reference sample nitrided during $5 \mathrm{~h}$ at $520{ }^{\circ} \mathrm{C}$ and a nitriding potential of $3.7 \mathrm{~atm}^{-1 / 2}$, measured by sparkle spectroscopy (OES analysis).

Figure 5 - Overview of the two faces of the $1 \%$-contaminated sample nitrided during $5 \mathrm{~h}$ at $520{ }^{\circ} \mathrm{C}$ and a nitriding potential of $3.7 \mathrm{~atm}^{-1 / 2}$. Microstructural observation (Fig. 2) and microhardness analyses (Fig. 3) are carried out at locations P1 and P2, while nitrogen content analysis (Fig. 6) are carried out at points A et B.

Figure 6 - Nitrogen content profiles of the reference and at two locations (A and B, Fig. 5) of the $1 \%$ oil-contaminated sample nitrided during $5 \mathrm{~h}$ at $520{ }^{\circ} \mathrm{C}$ and a nitriding potential of $3.7 \mathrm{~atm}^{-1 / 2}$ (OES analysis).

Figure 7 - SEM-BSE observations of $1 \%$-water diluted machining oil residues at the surface of polished samples after heating at the nitriding temperatures $\left(520^{\circ} \mathrm{C}\right)$ followed by direct slow cooling to room temperature under inert gas.

Figure 8 - EDS mapping of machining oil residues heated at $520^{\circ} \mathrm{C}$ : Carbon, Calcium, Sulphur, Oxygen and Silicon.

Figure 9 - Mass gain profiles of the reference, carbon contaminated and carbon contaminated submitted to pre-oxidation samples nitrided during $5 \mathrm{~h}$ at $520{ }^{\circ} \mathrm{C}$ and a nitriding potential of $3.7 \mathrm{~atm}^{-1 / 2}$.

Figure 10-Microhardness profiles and overview of the exposed face of the carbon contaminated sample nitrided during $5 \mathrm{~h}$ at $520{ }^{\circ} \mathrm{C}$ and a nitriding potential of $3.7 \mathrm{~atm}^{-1 / 2}$.

Figure 11 - Optical microscope observations (2\%-nital etching) at two different locations A and $\mathrm{B}$ (indicated in Fig. 10) of the exposed face of the carbon contaminated sample nitrided during $5 \mathrm{~h}$ at $520{ }^{\circ} \mathrm{C}$ and a nitriding potential of $3.7 \mathrm{~atm}^{-1 / 2}$.

Figure 12 - Mass gain profiles of the reference and pre-oxidized samples nitrided during $5 \mathrm{~h}$ at $520^{\circ} \mathrm{C}$ and a nitriding potential of $3.7 \mathrm{~atm}^{-1 / 2}$.

Figure 13 - Mass gain profiles of the reference, oil contaminated and pre-oxidized after oil contamination samples nitrided during $5 \mathrm{~h}$ at $520{ }^{\circ} \mathrm{C}$ and a nitriding potential of $3.7 \mathrm{~atm}^{-1 / 2}$. 
Figure 14 - Optical microscope observations (2\%-nital etching) of the sample contaminated by $5 \%$ oil and pre-oxidized (A) and of the sample pre-oxidized after a carbon contamination (B) followed by nitriding during $5 \mathrm{~h}$ at $520^{\circ} \mathrm{C}$ and a nitriding potential of $3.7 \mathrm{~atm}^{-1 / 2}$.

Figure 15 - Microhardness profiles of the reference, $5 \%$ oil-contaminated and $5 \%$ oilcontaminated and pre-oxidized samples nitrided during $5 \mathrm{~h}$ at $520{ }^{\circ} \mathrm{C}$ and a nitriding potential of $3.7 \mathrm{~atm}^{-1 / 2}$.

Figure 16 - Microhardness profiles of the reference and of the exposed face of the carbon contaminated samples nitrided during $5 \mathrm{~h}$ at $520^{\circ} \mathrm{C}$ and a nitriding potential of $3.7 \mathrm{~atm}^{-1 / 2}$.

Figure 17 - Mass gain profiles of the reference and oil contaminated carbon prepared with urea samples nitrided during $5 \mathrm{~h}$ at $520^{\circ} \mathrm{C}$ and a nitriding potential of $3.7 \mathrm{~atm}^{-1 / 2}$.

Figure 18 - Microhardness profiles of the reference and oil contaminated carbon prepared with urea samples nitrided during $5 \mathrm{~h}$ at $520{ }^{\circ} \mathrm{C}$ and a nitriding potential of $3.7 \mathrm{~atm}^{-1 / 2}$.

Figure 19 - Mass gain profiles of the reference and oil contaminated carbon prepared with ammonium chloride samples nitrided during $5 \mathrm{~h}$ at $520^{\circ} \mathrm{C}$ and a nitriding potential of $3.7 \mathrm{~atm}^{-}$ $1 / 2$

Figure 20 - Microhardness profiles of the reference and oil contaminated carbon prepared with ammonium chloride samples nitrided during $5 \mathrm{~h}$ at $520{ }^{\circ} \mathrm{C}$ and a nitriding potential of 3.7 $\operatorname{atm}^{-1 / 2}$.

Figure 21 - Summary of the final mass gain of the reference, oil-contaminated and oilcontaminated prepared with oxygen/urea/ammonium chloride samples nitrided during $5 \mathrm{~h}$ at $520{ }^{\circ} \mathrm{C}$ and a nitriding potential of $3.7 \mathrm{~atm}^{-1 / 2}$. 
Figures

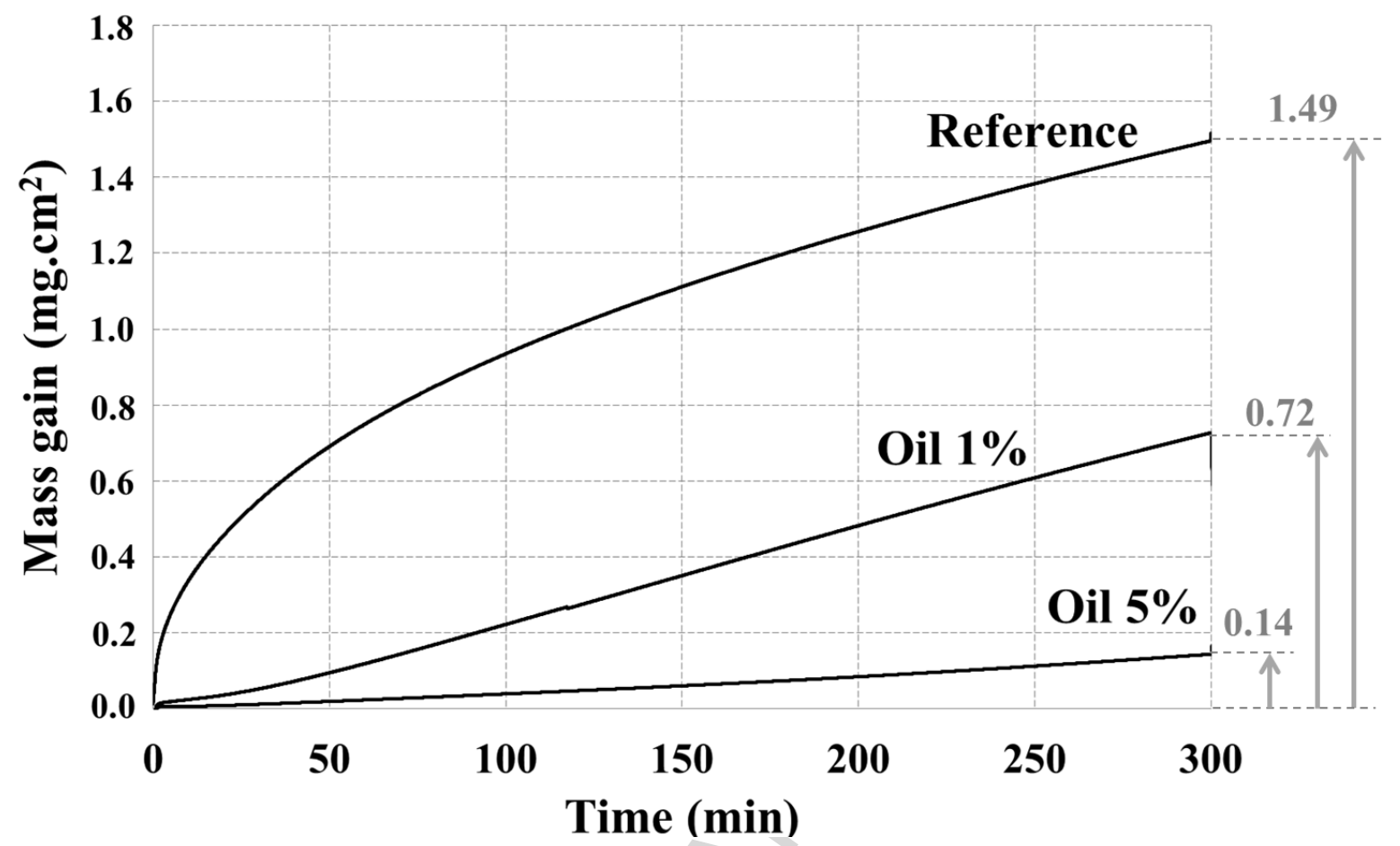

Figure 1 


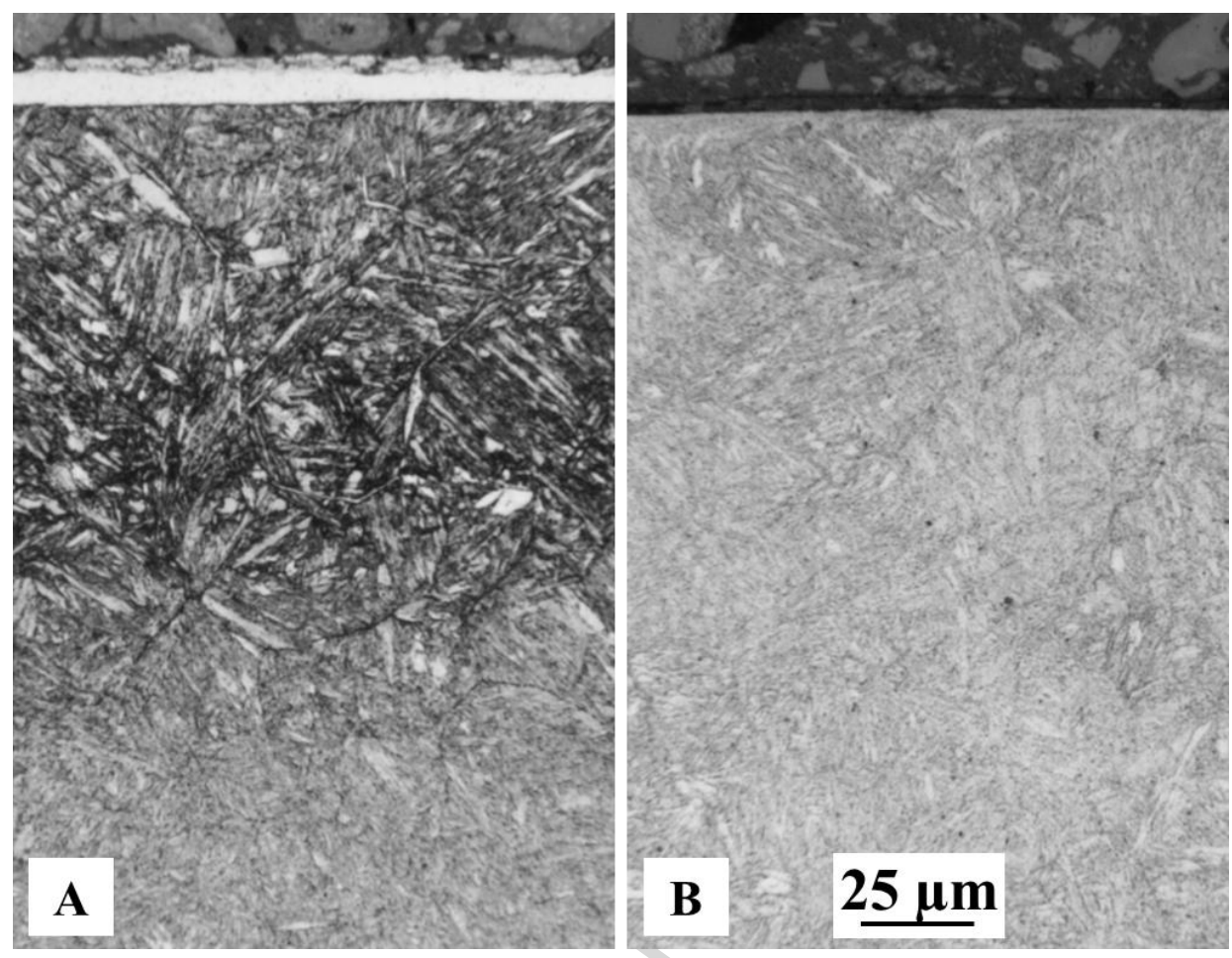

Figure 2

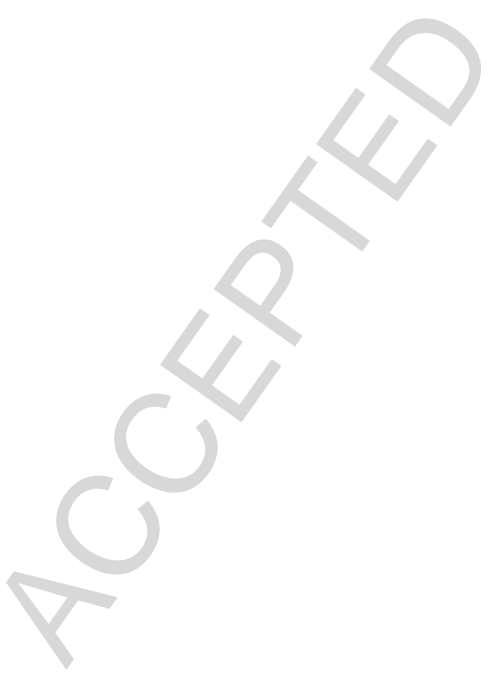




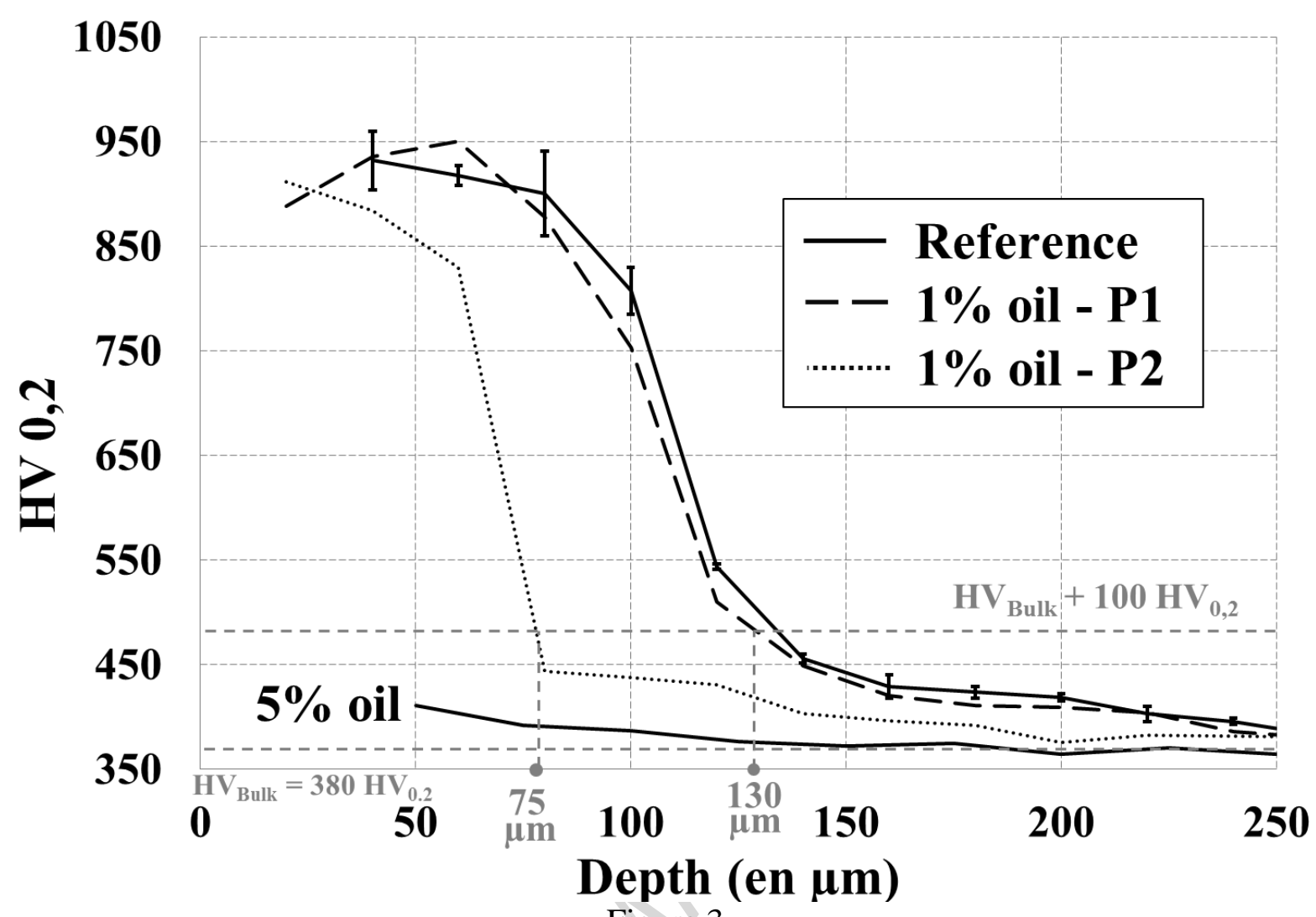

Figure 3 


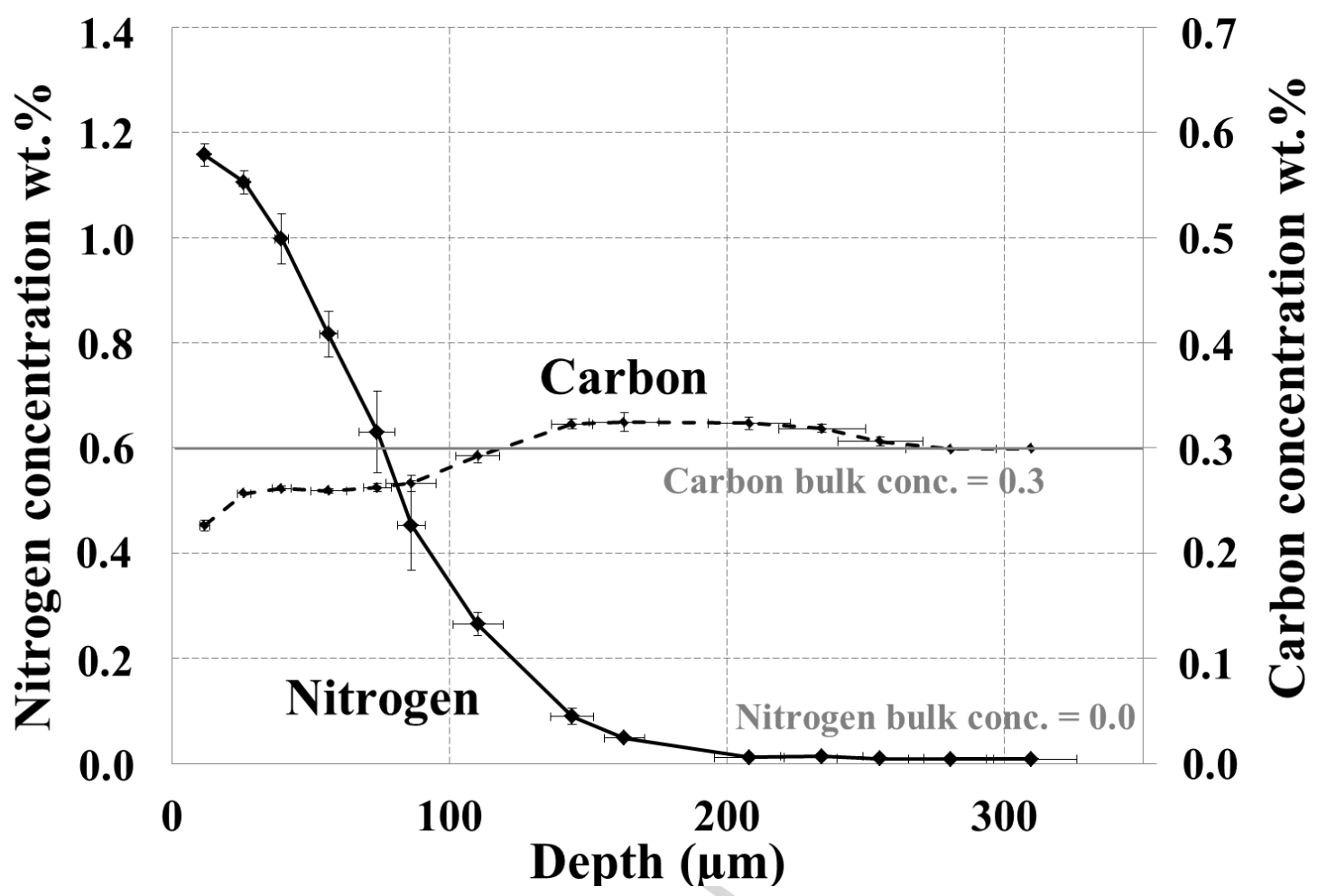

Figure 4 


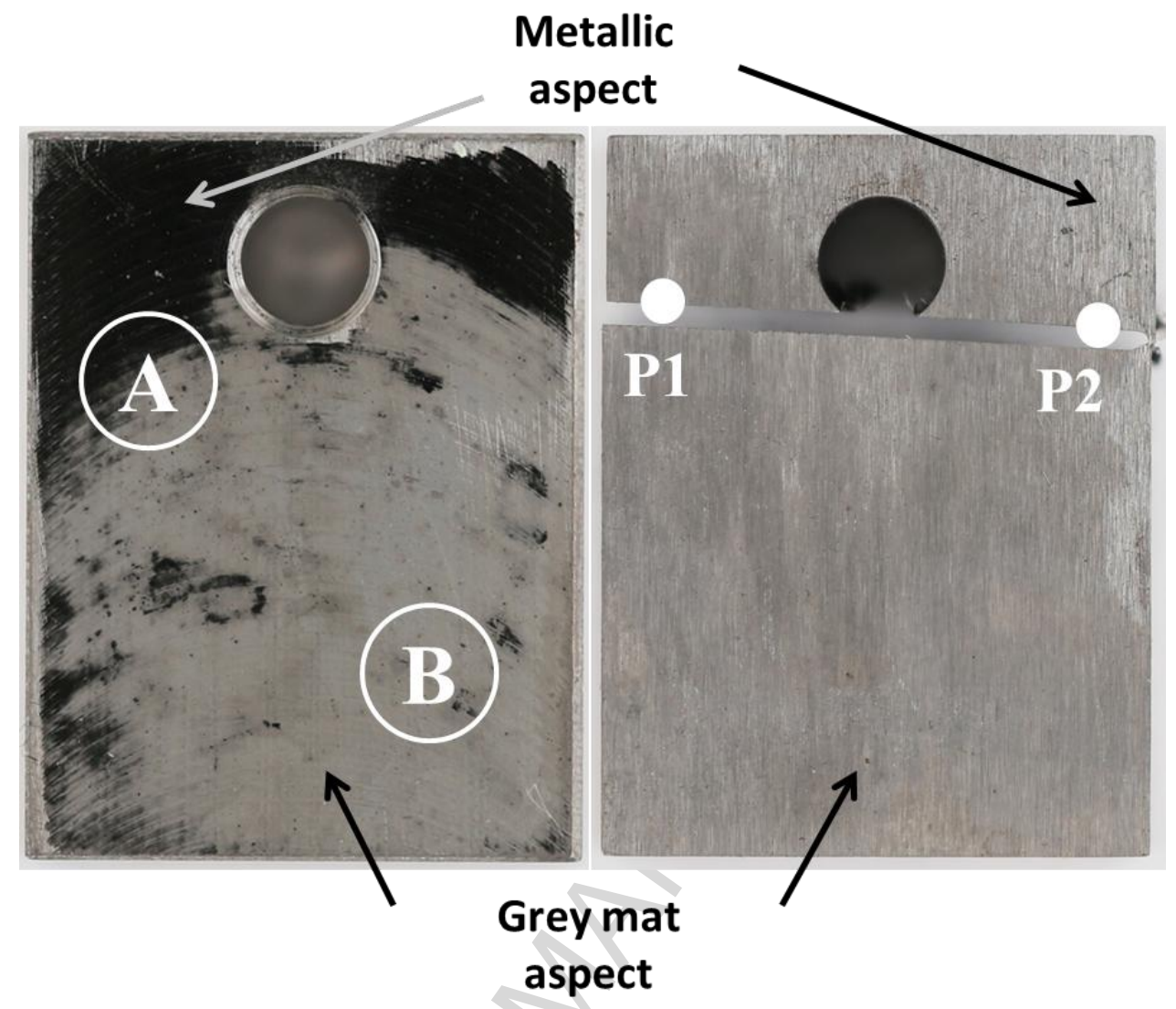

Figure 5 


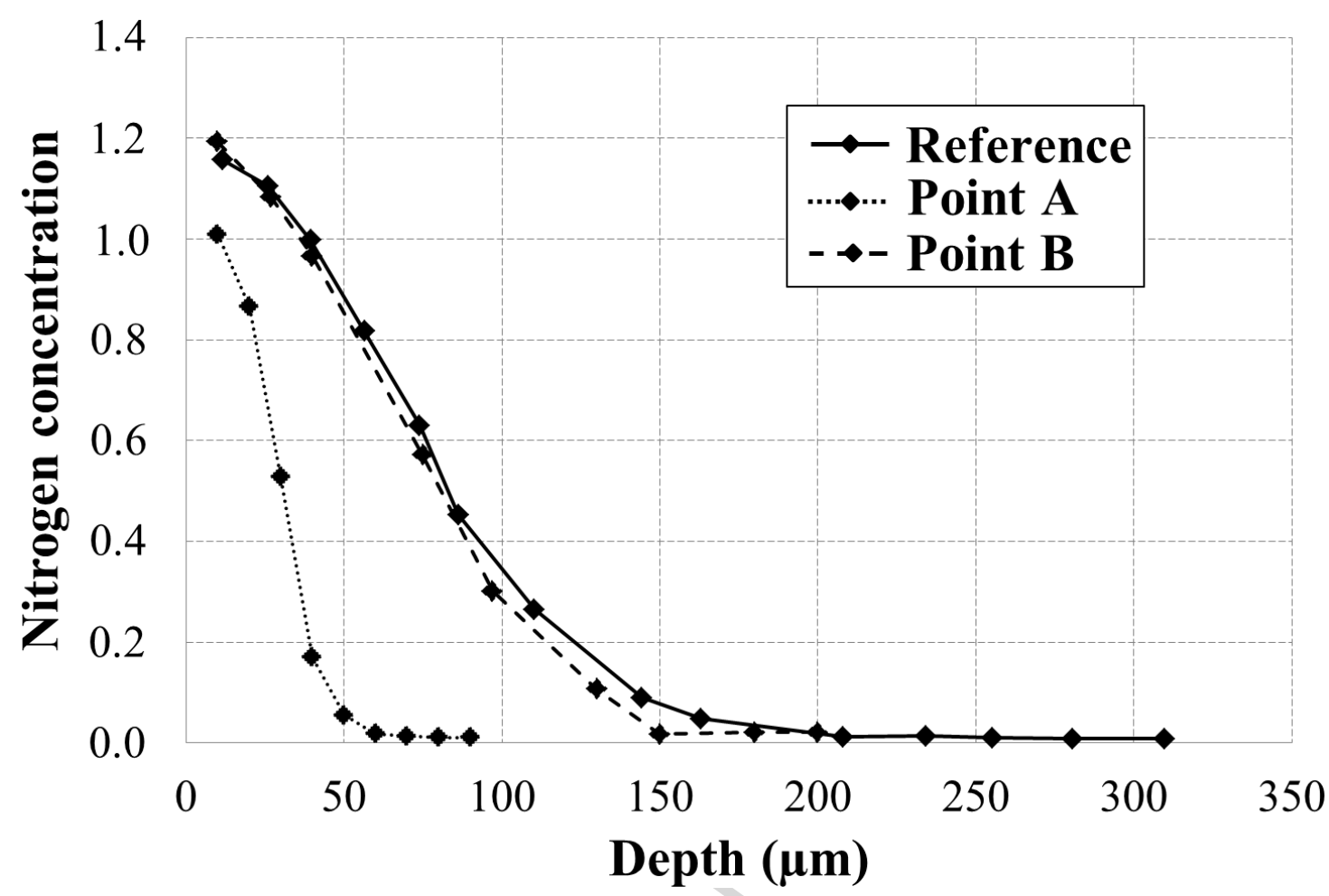

Figure 6 


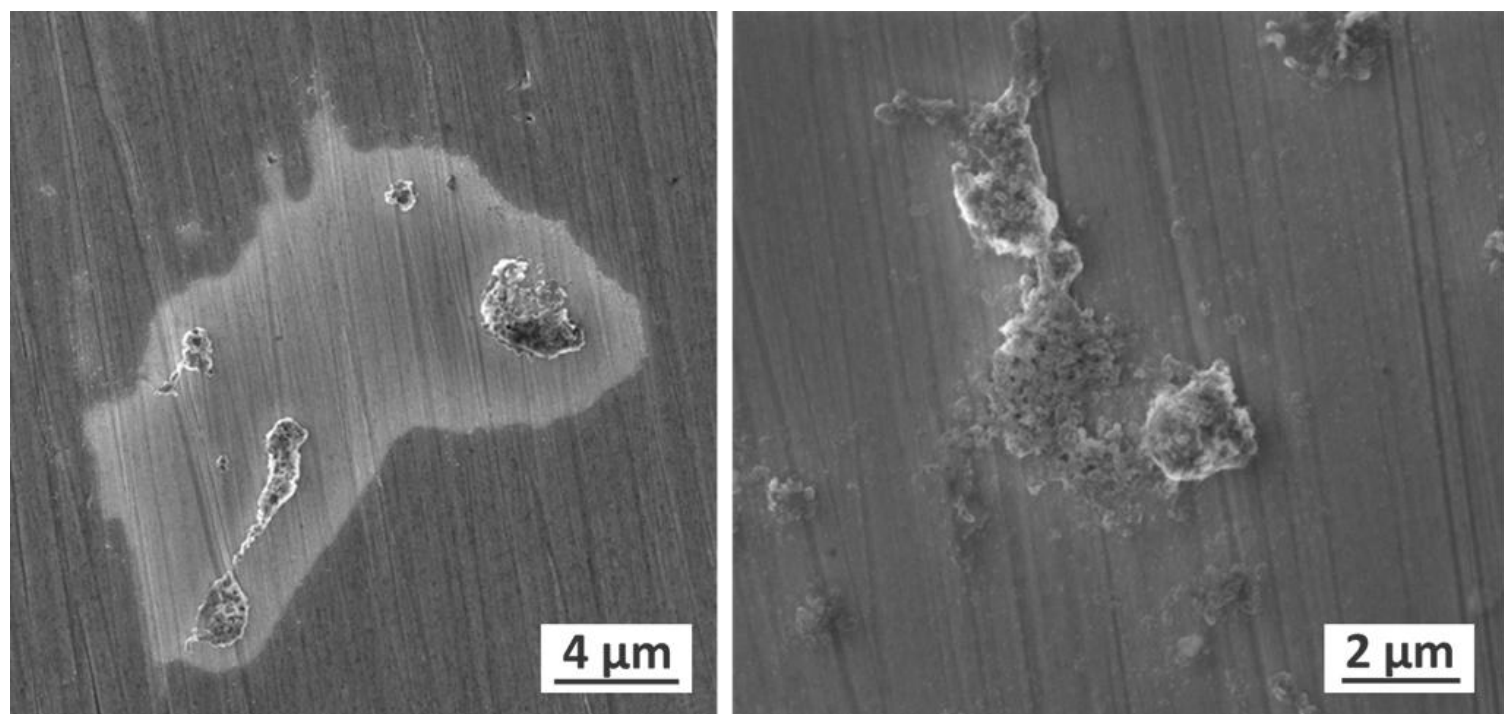

Figure 7

Page 34 

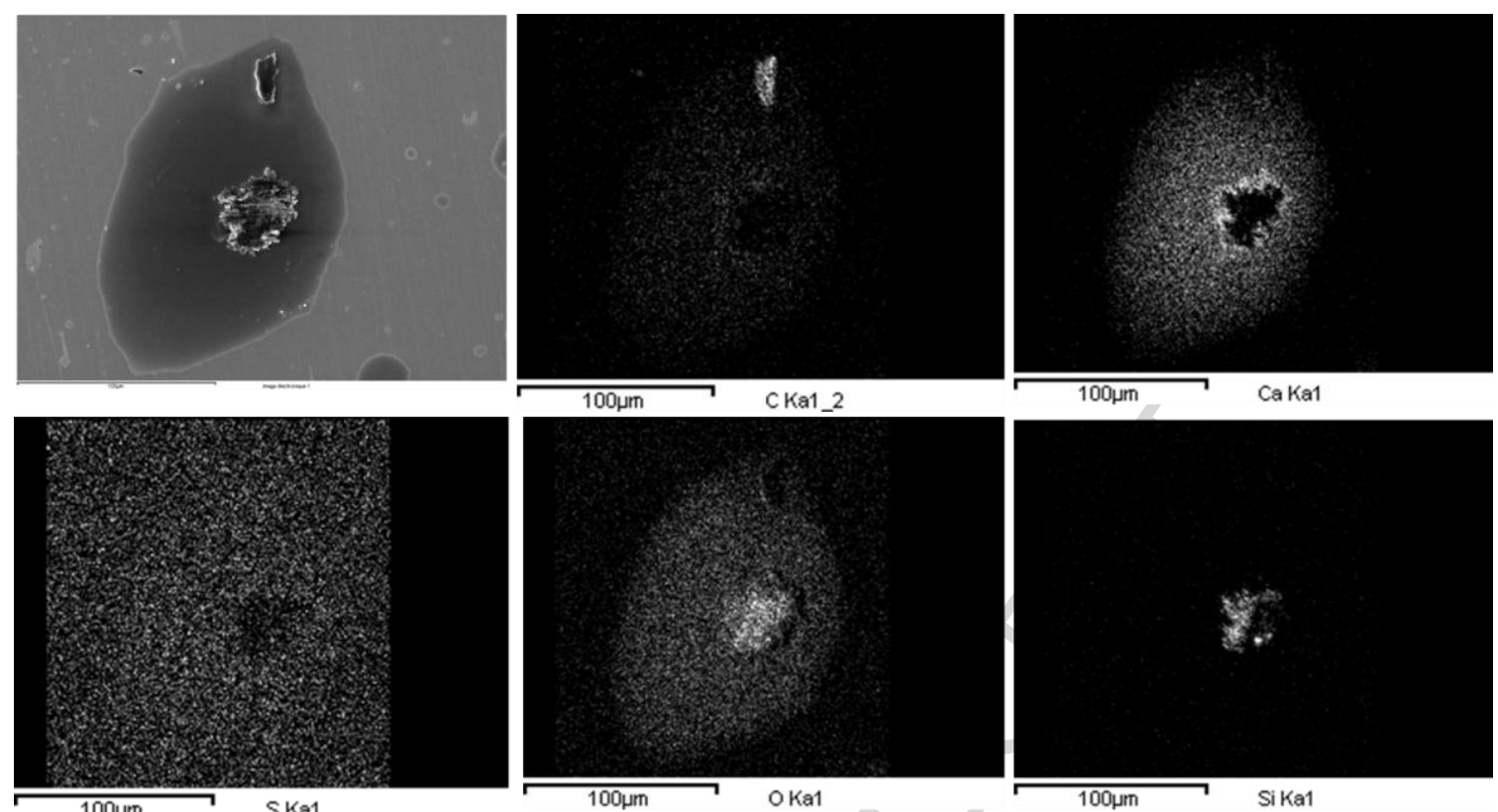

Figure 8 


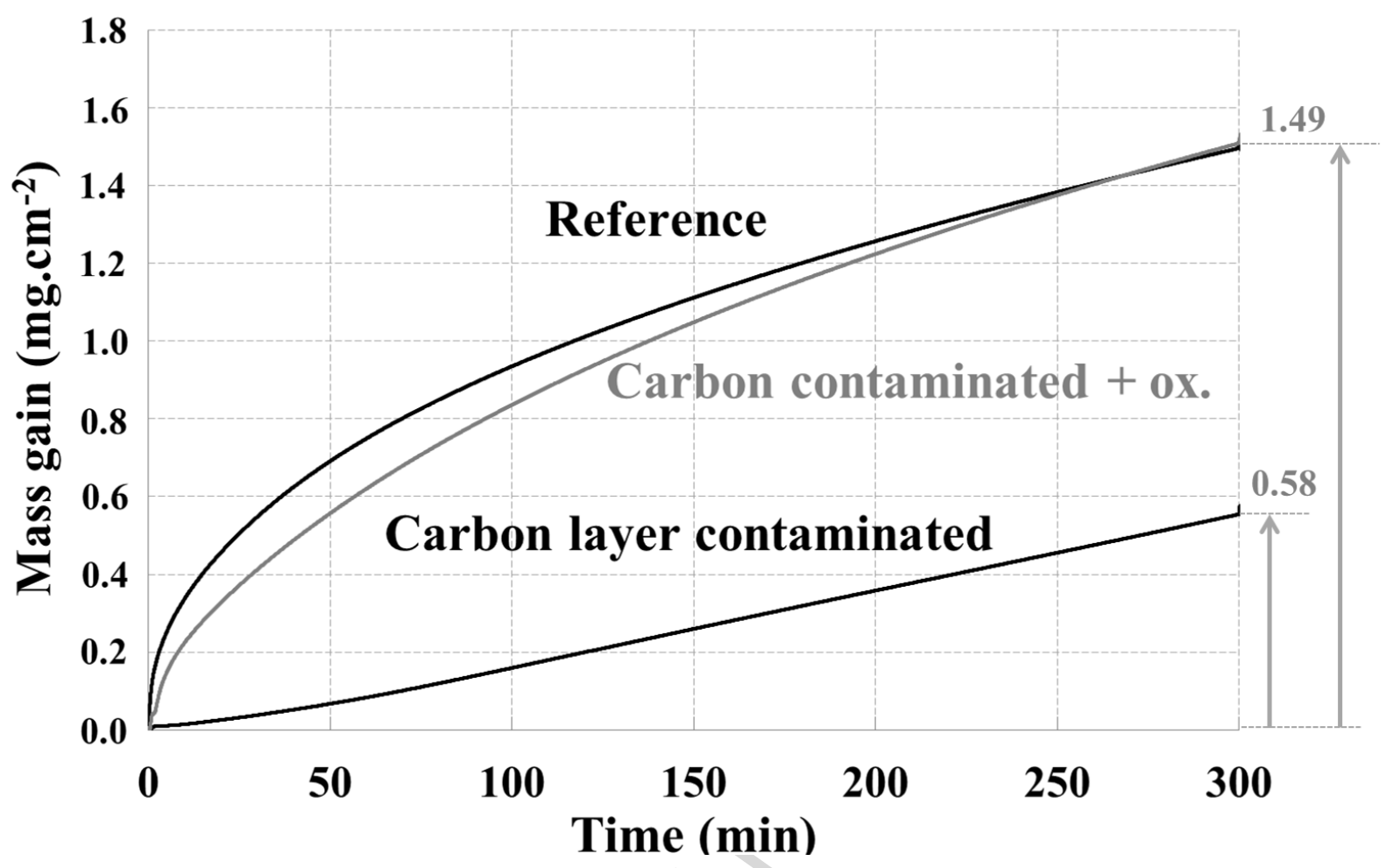

Figure 9 

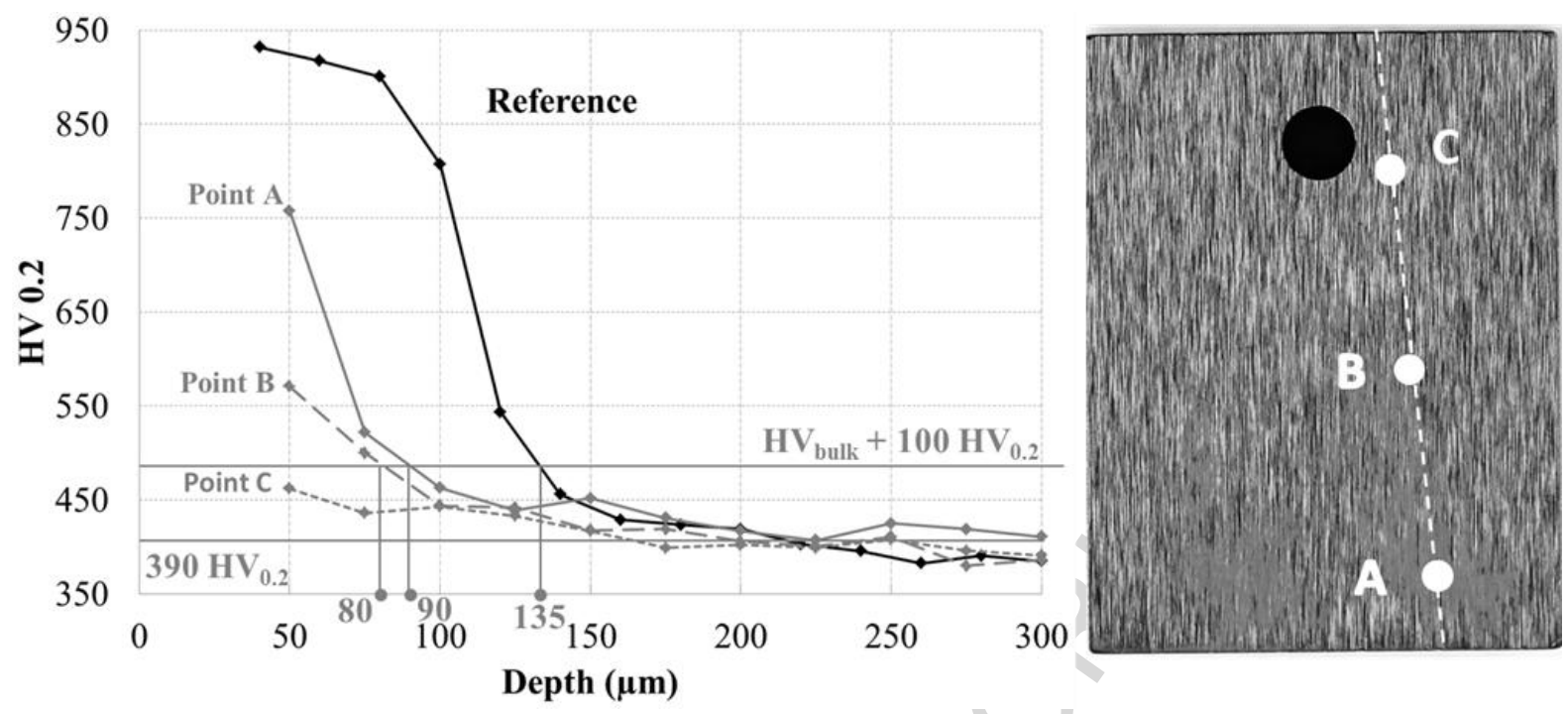

Figure 10 

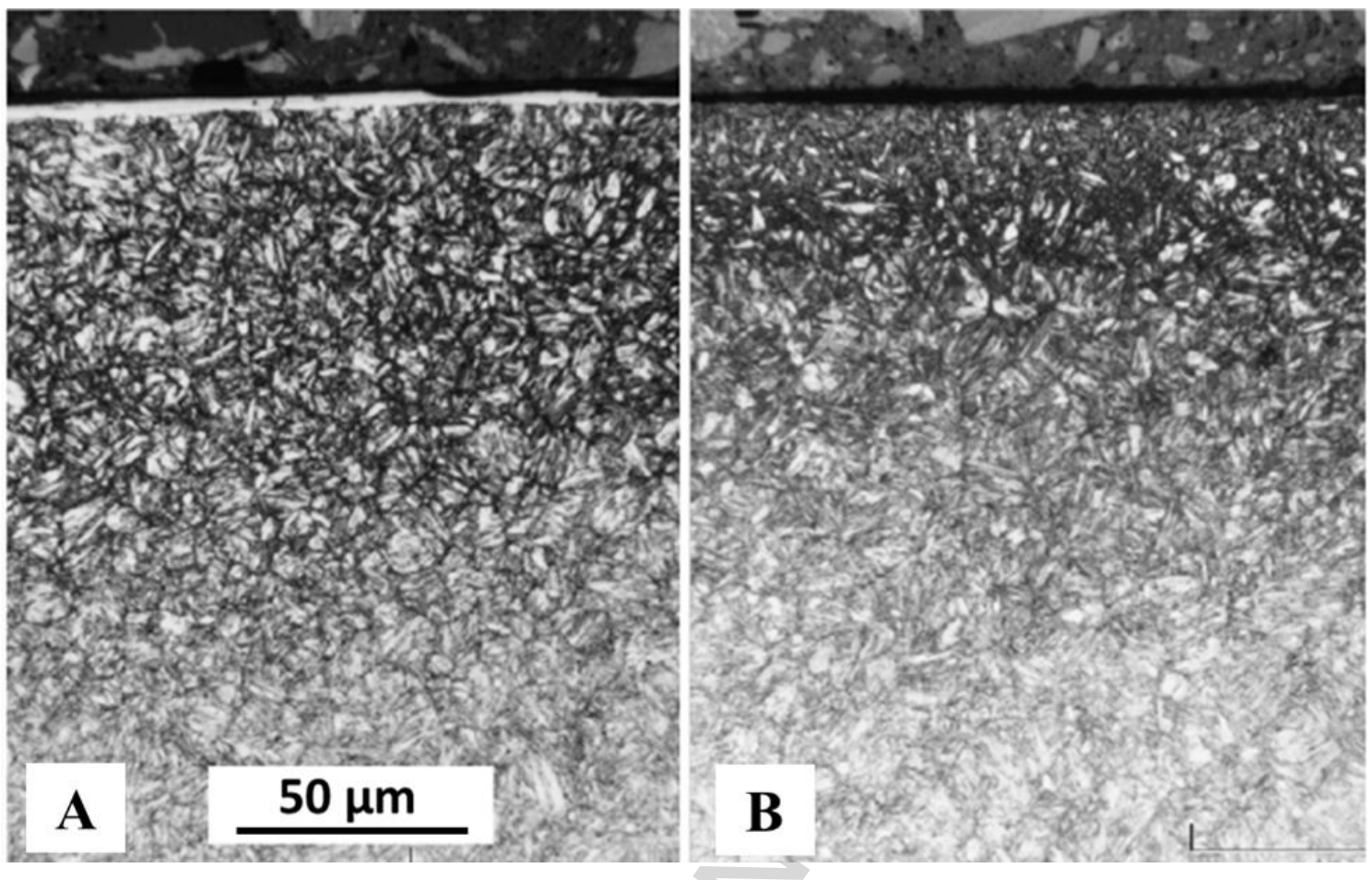

Figure 11 


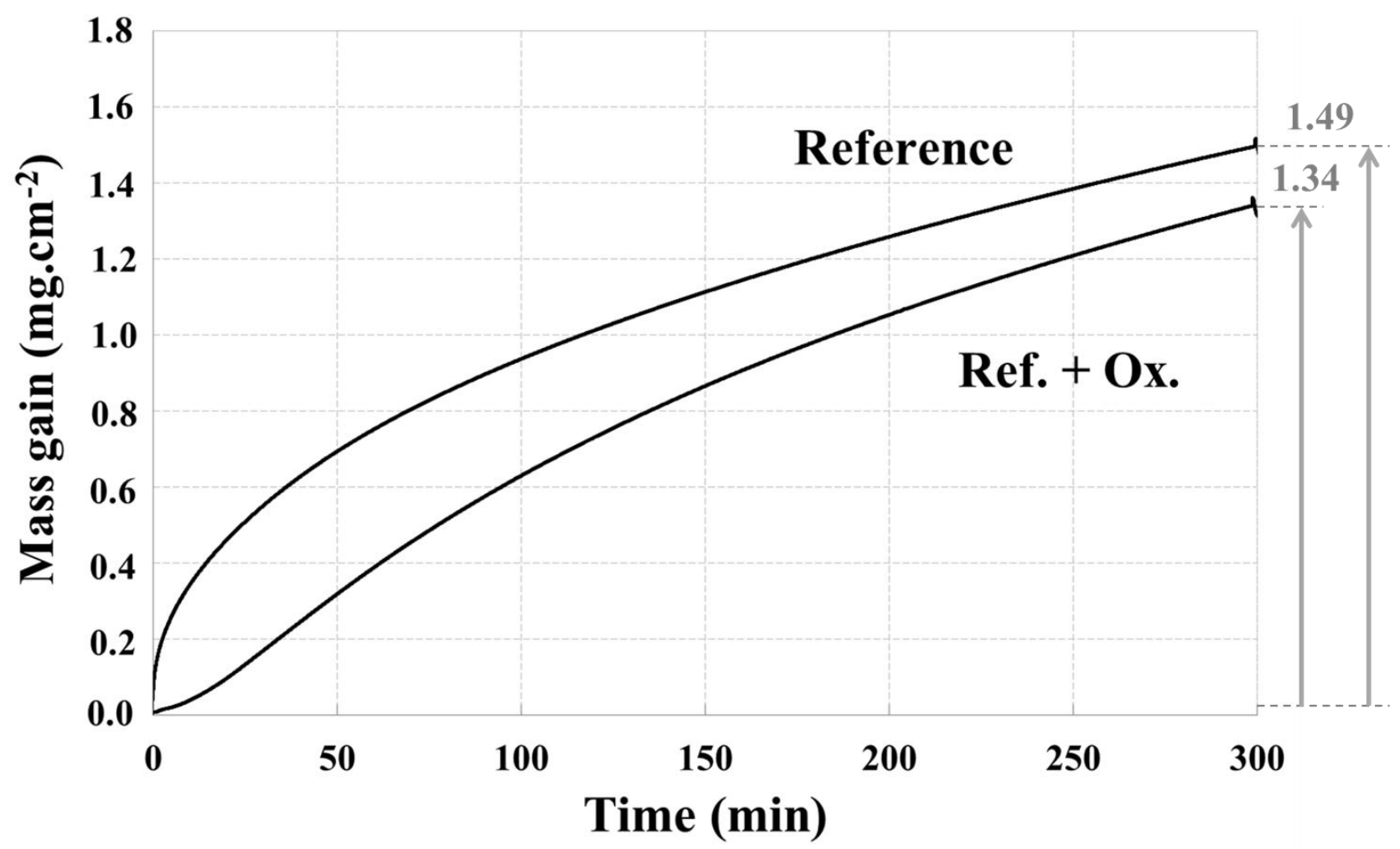

Figure 12 


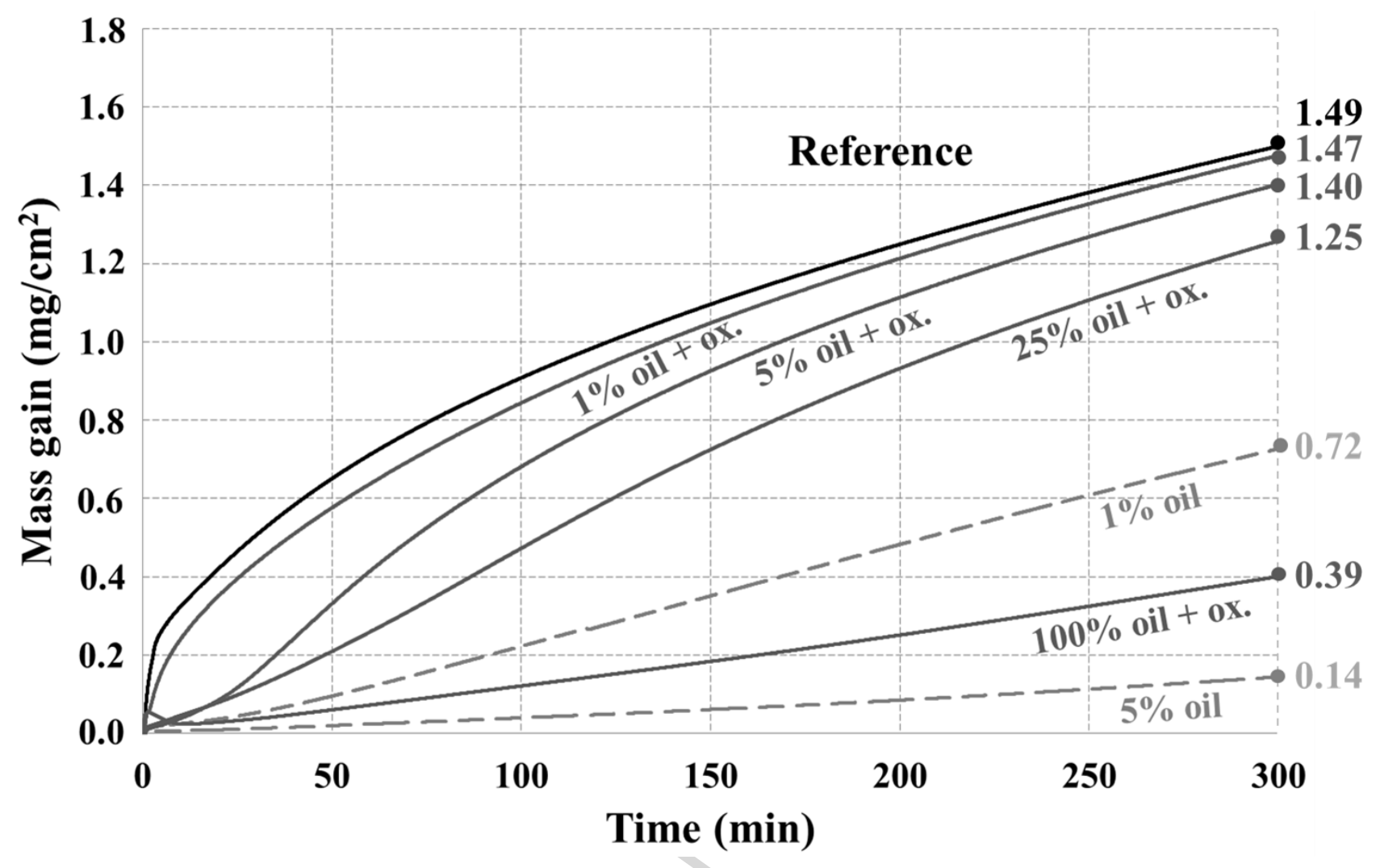

Figure 13 


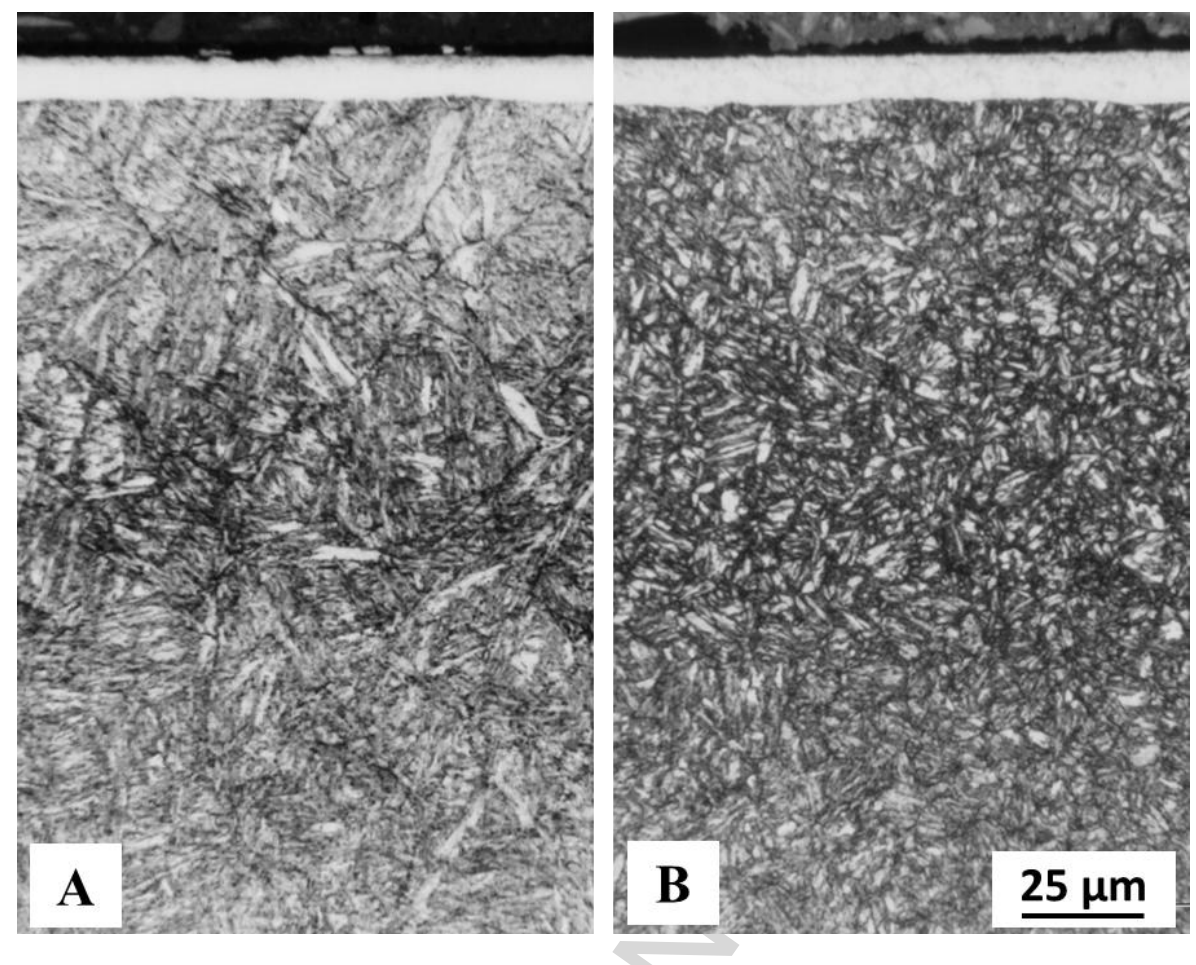

Figure 14 


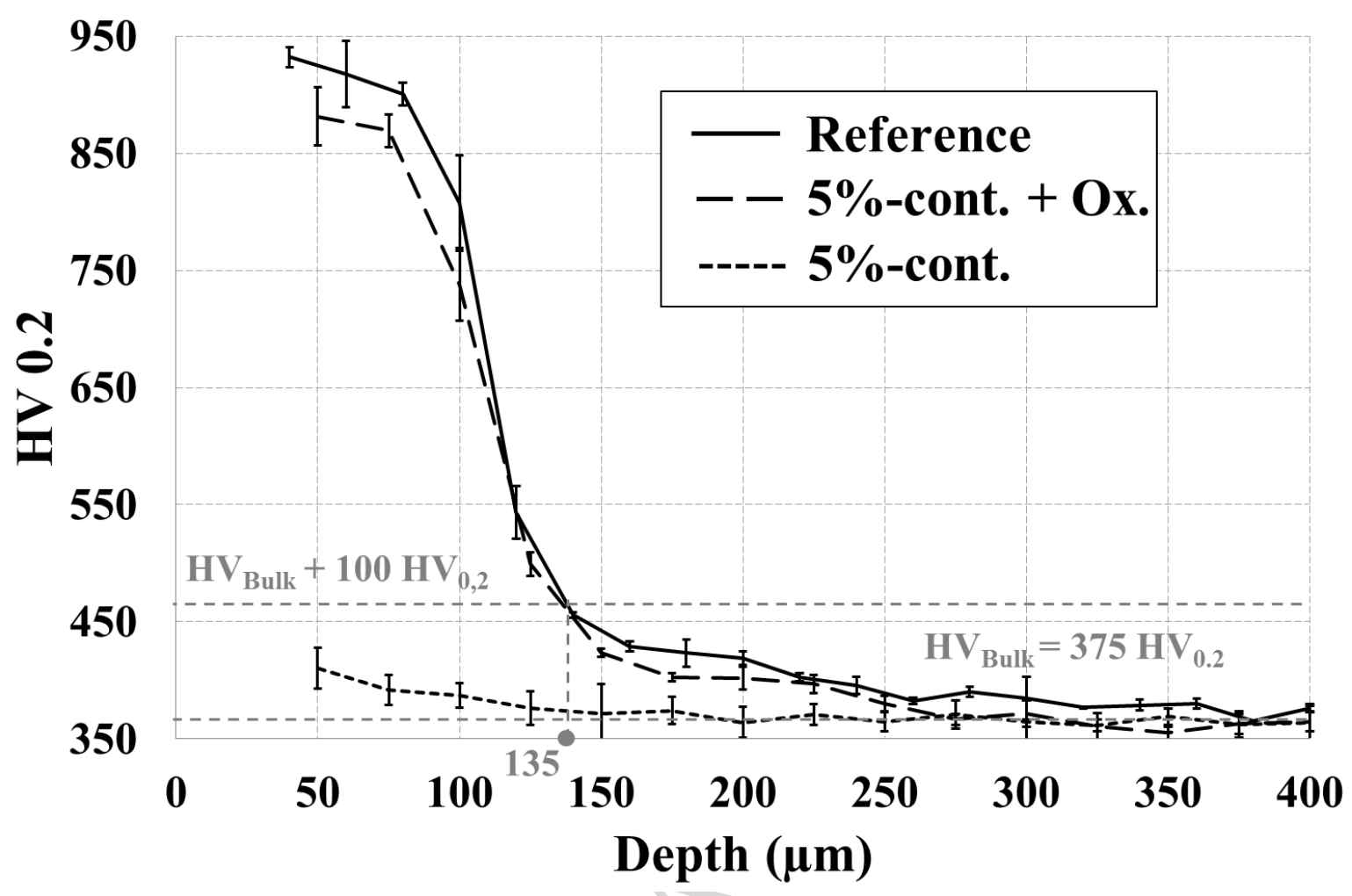

Figure 15 


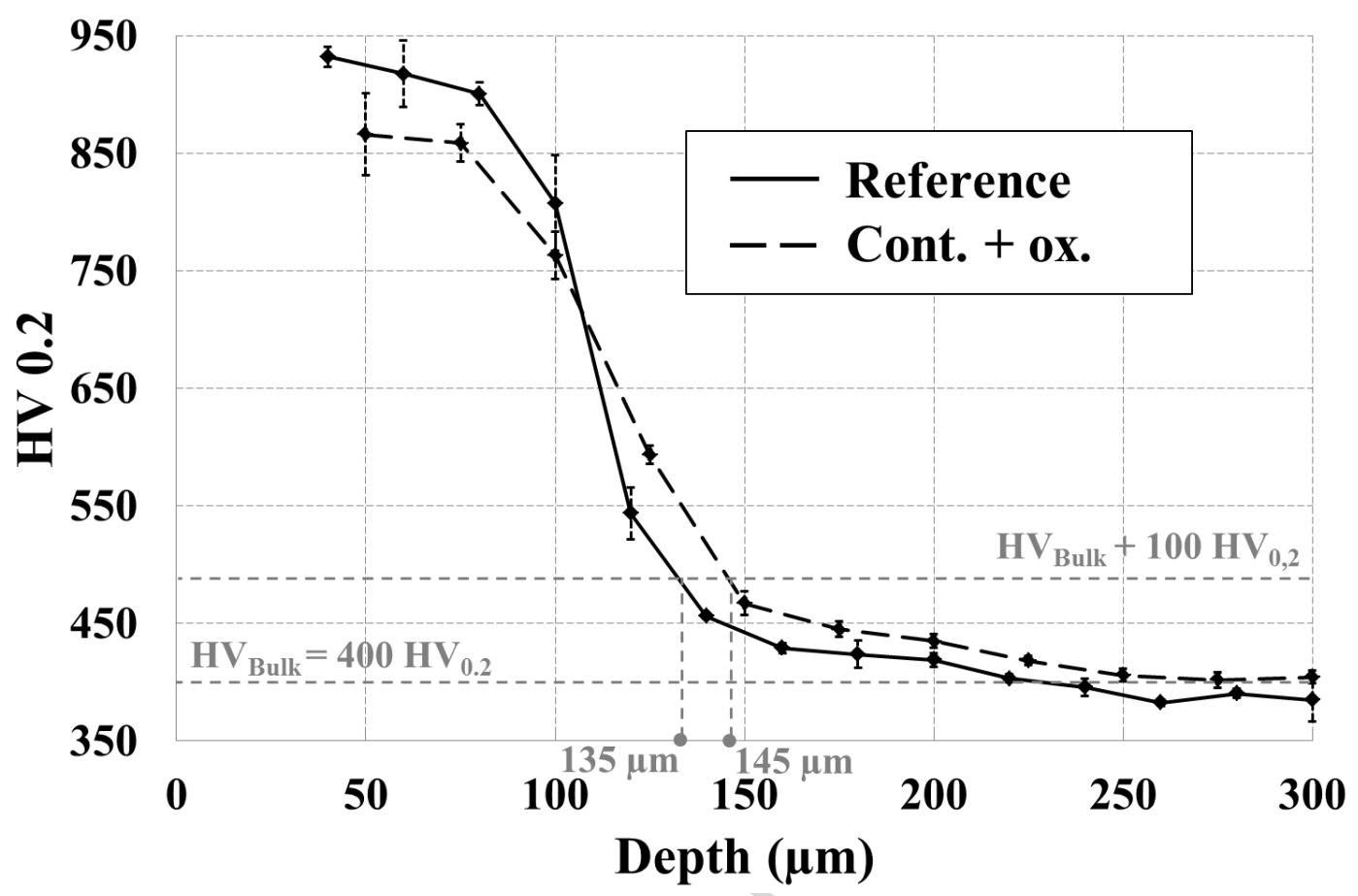

Figure 16 


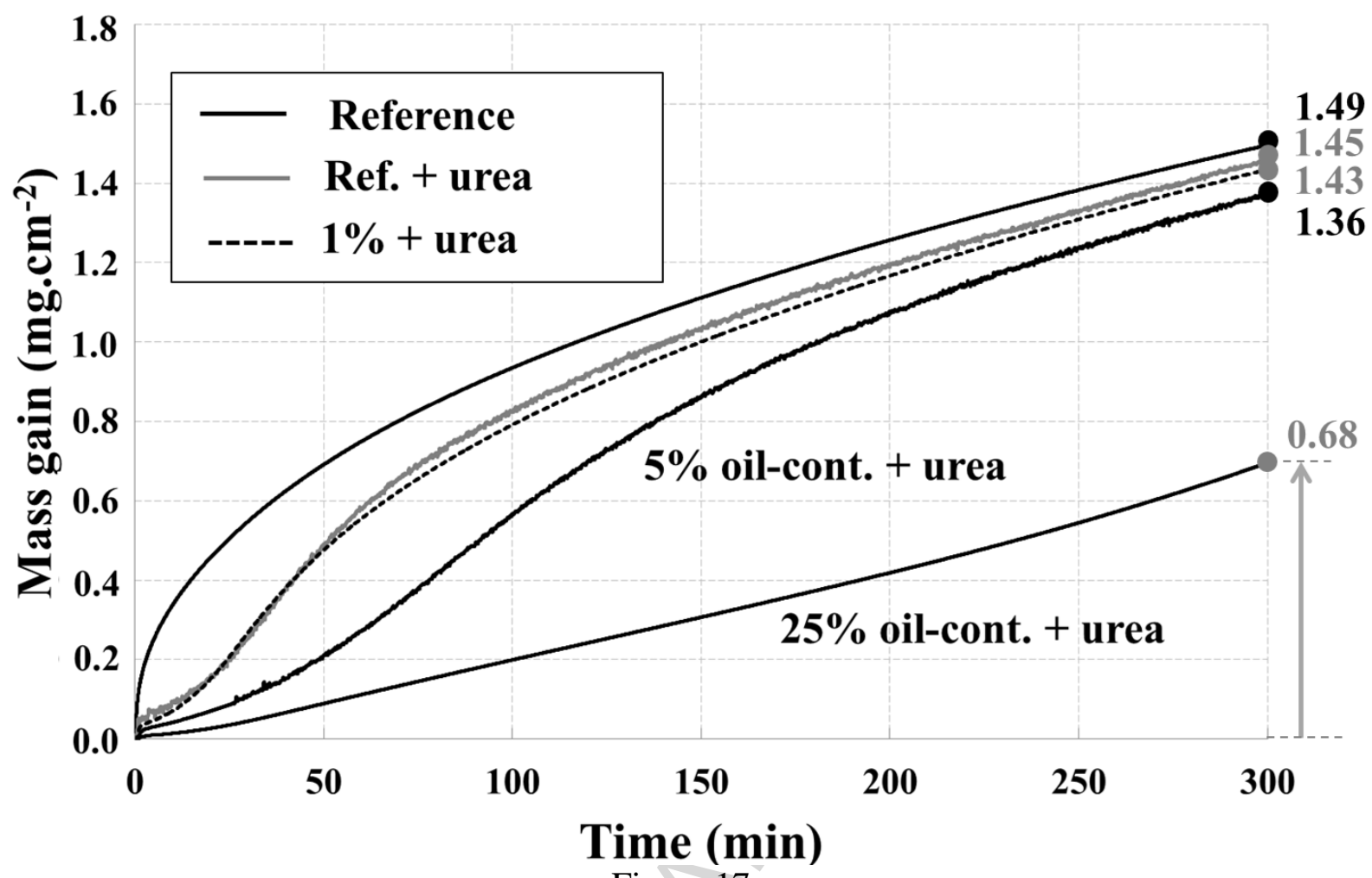

Figure 17 


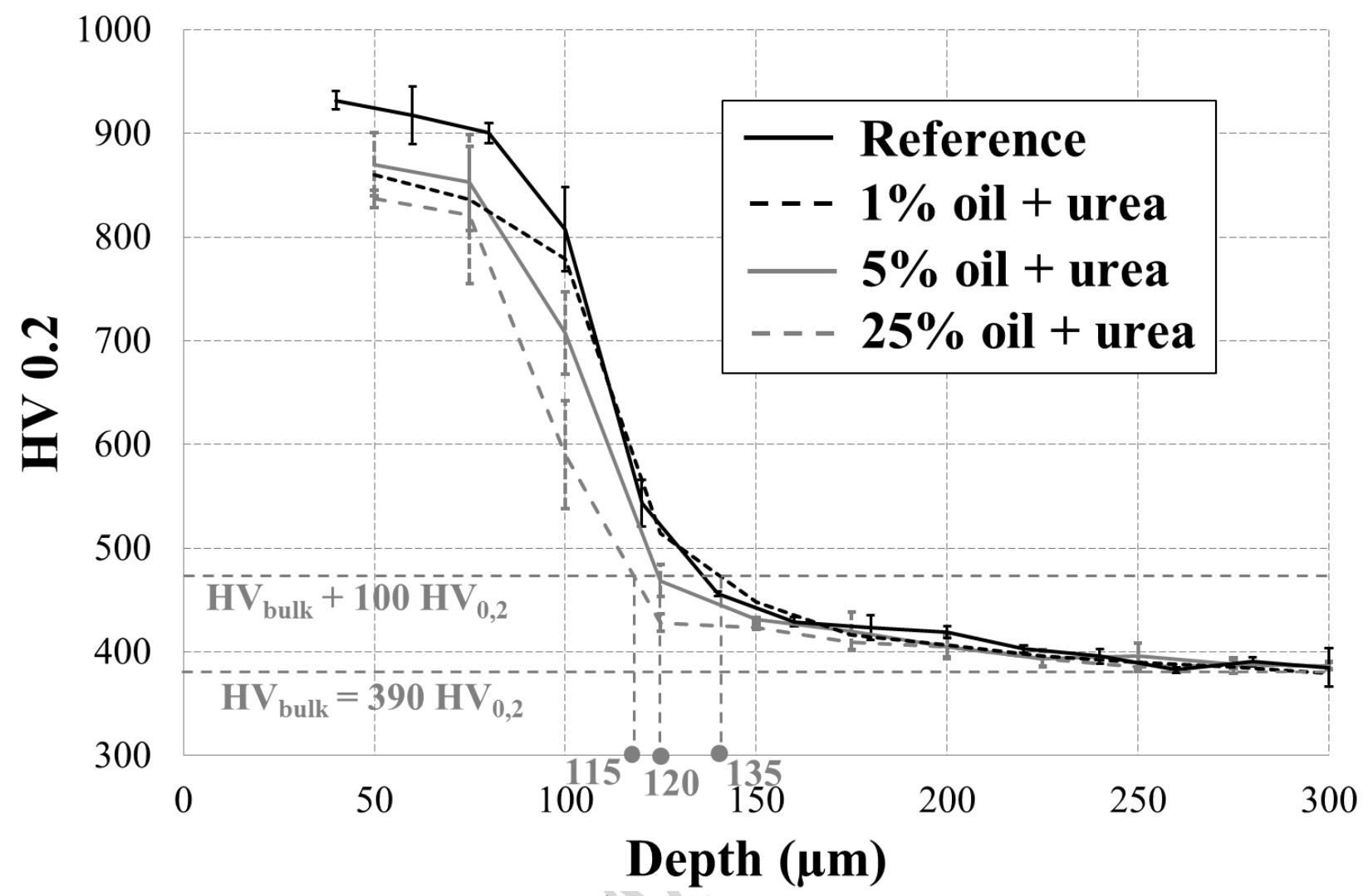

Figure 18 


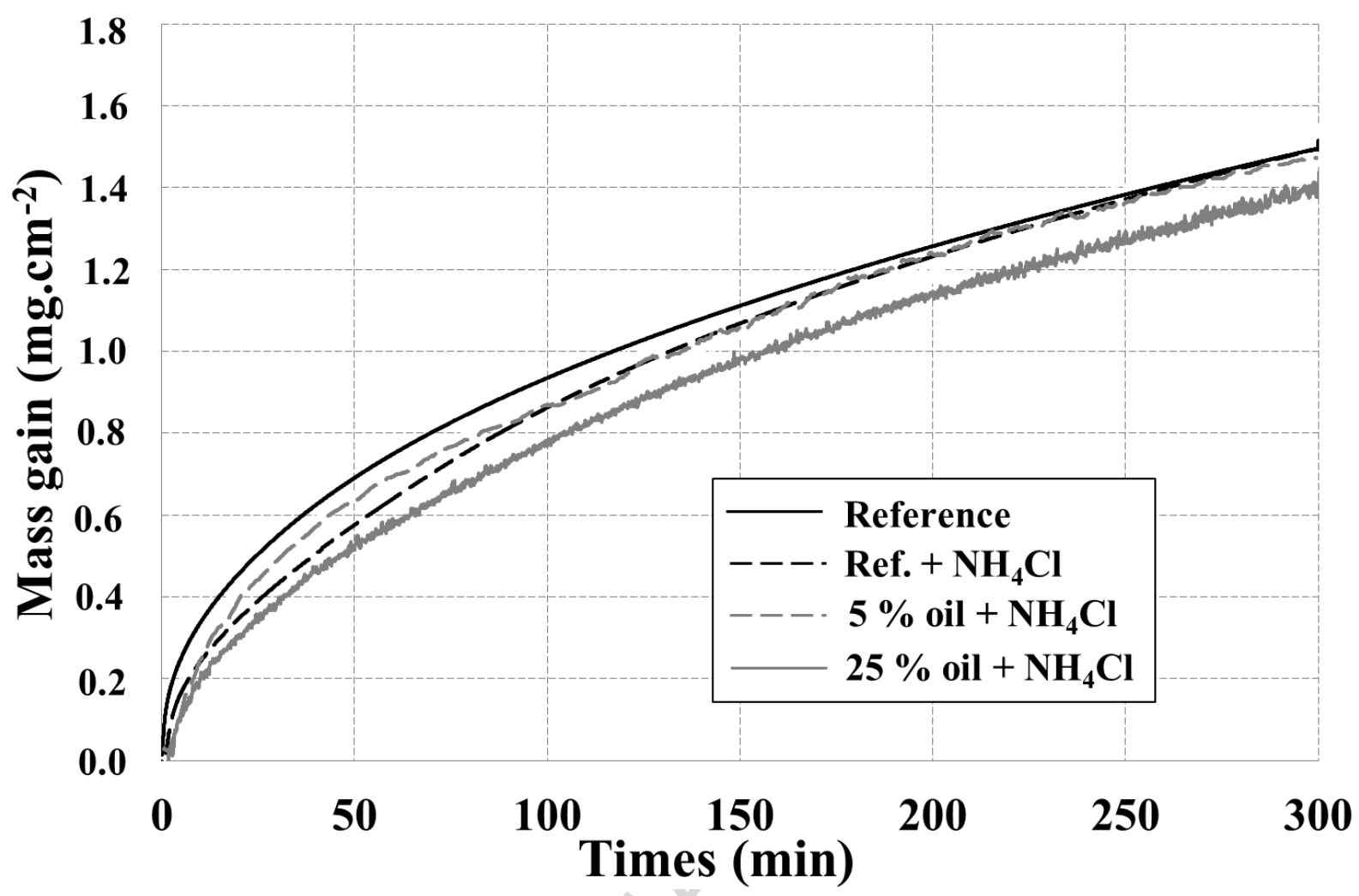

Figure 19 


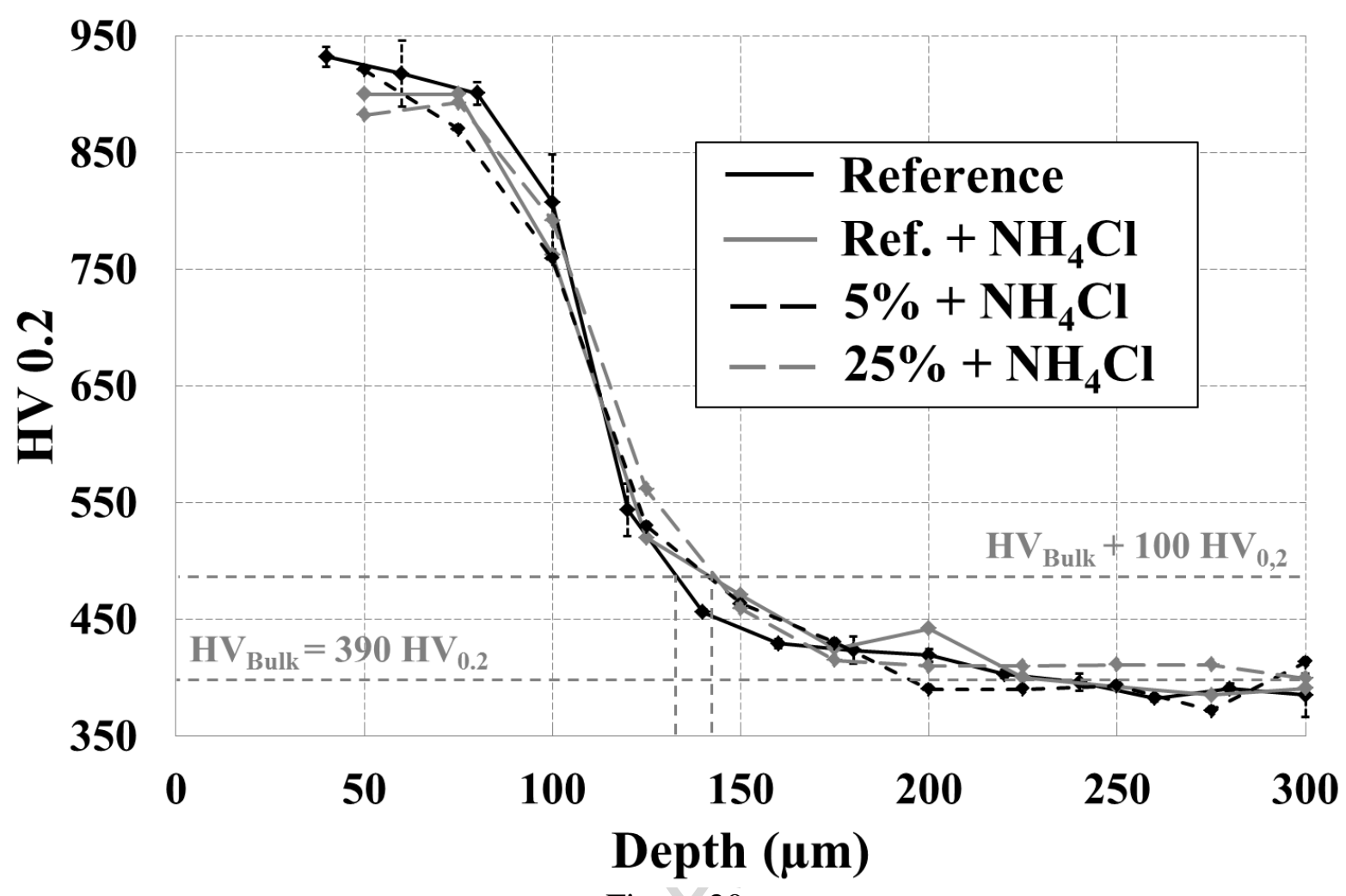

Figure 20 


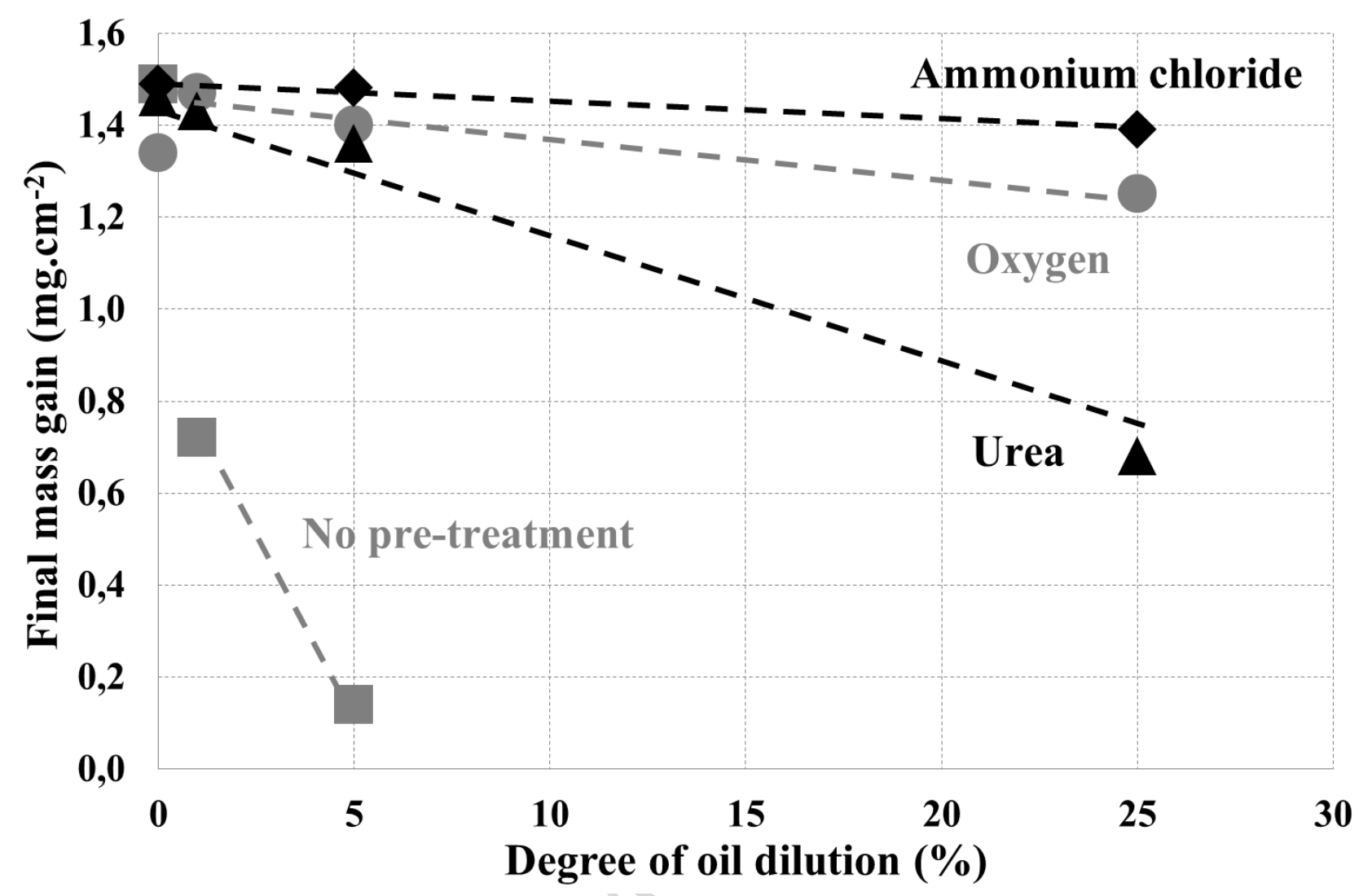

Figure 21 


\section{List of Table}

Table I: Chemical composition of the considered 33CrMoV12-9 grade steel obtained by spark optical emission spectrometry.

\begin{tabular}{|c|c|c|c|c|c|}
\hline \multicolumn{6}{|c|}{ Composition (wt. \%) } \\
\hline C & Cr & Mo & V & Mn & Fe \\
\hline 0.30 & 2.97 & 0.91 & 0.28 & 0.51 & balance \\
\hline
\end{tabular}


Table II: Summary of the final mass gain $\left[\mathrm{mg} . \mathrm{cm}^{-2}\right]$ obtained by thermogravimetric analysis.

\begin{tabular}{|c|c|c|c|c|}
\hline & - & Oxidation & Urea & $\mathbf{N H}_{4} \mathbf{C l}$ \\
\hline Reference & 1.49 & 1.34 & 1.46 & 1.49 \\
\hline Oil 1 \% & 0.72 & 1.47 & 1.43 & - \\
\hline Oil 5\% & 0.14 & 1.40 & 1.36 & 1.48 \\
\hline Oil 25 \% & - & 1.25 & 0.68 & 1.39 \\
\hline Pure oil & - & 0.39 & - & - \\
\hline Carbon deposit & 0.58 & 1.49 & - & - \\
\hline
\end{tabular}


Table III: Summary of the effective depth $[\mu \mathrm{m}]$ obtained by microhardness measurements.

\begin{tabular}{|c|c|c|c|c|}
\hline & - & Pre-oxidation & Urea & NH4 $_{4}$ I \\
\hline Reference & 135 & - & - & - \\
\hline Oil 1 \% & 75 to 130 & 135 & 140 & - \\
\hline Oil 5\% & 0 & 135 & 120 & 140 \\
\hline Oil 25 \% & - & & 115 & 145 \\
\hline Carbon deposit & 0 to 90 & 145 & - & - \\
\hline
\end{tabular}




\section{Highlights}

- The impact of an oil-based contamination on nitriding properties is determined.

- Thermogravimetric, microstructural and mechanical analyses are used.

- Explanations on the oil-contamination are proposed.

- Surface activation capacities of in-situ treatment are analysed.

- In-situ treatments are based on oxygen, urea or ammonium chloride. 